\title{
The Role of T Cell Immunoglobulin Mucin Domains 1 and 4 in a Herpes Simplex Virus-Induced Behçet's Disease Mouse Model
}

\author{
Ju A. Shim, ${ }^{1}$ Eun-So Lee, ${ }^{2}$ Bunsoon Choi, ${ }^{1}$ and Seonghyang Sohn ${ }^{1,3}$ \\ ${ }^{1}$ Laboratory of Cell Biology, Ajou University Institute for Medical Sciences, Suwon 443-721, Republic of Korea \\ ${ }^{2}$ Department of Dermatology, Ajou University, School of Medicine, Suwon 443-721, Republic of Korea \\ ${ }^{3}$ Brain Korea 21 Project for Medical Science, Suwon 443-721, Republic of Korea \\ Correspondence should be addressed to Seonghyang Sohn; sohnsh@ajou.ac.kr
}

Received 31 May 2013; Revised 24 October 2013; Accepted 18 November 2013

Academic Editor: Dennis Daniel Taub

Copyright (C) 2013 Ju A. Shim et al. This is an open access article distributed under the Creative Commons Attribution License, which permits unrestricted use, distribution, and reproduction in any medium, provided the original work is properly cited.

\begin{abstract}
The $\mathrm{T}$ cell immunoglobulin mucin (TIM) proteins regulate $\mathrm{T}$ cell activation and tolerance. TIM-1 plays an important role in the regulation of immune responses and the development of autoimmune diseases. TIM-4 is a natural ligand of TIM-1, and the interaction of TIM-1 and TIM-4 is involved in the regulation of T helper (Th) cell responses and modulation of the Th1/Th2 cytokine balance. Behçet's disease (BD) is a chronic, multisystemic inflammatory disorder with arthritic, intestinal, mucocutaneous, ocular, vascular, and central nervous system involvement. Tim-1 expression was lower in a herpes simplex virus-induced BD mouse model compared to that in asymptomatic BD normal (BDN) mice. Tim-4 expression was higher in BD mice than that in BDN mice. In this study, we investigated the Tim expression in a BD mouse model with BD-like symptoms. Tim-1 and Tim-4 expression was regulated by an expression vector or siRNA injected into the BD mouse model. The Tim-1 vector injected into BD mice resulted in changes in BD-like symptoms and decreased the severity score. Treatment with Tim- 4 siRNA also improved BD-like symptoms and decreased the severity score accompanied by upregulation of regulatory T cells. We showed that regulating Tim-1 or Tim- 4 affected BD-like symptoms in mice.
\end{abstract}

\section{Introduction}

The T cell immunoglobulin and mucin domain (TIM) family is located on chromosome 11B1.1 in mice and consists of several members (Tim-1-8). In humans it is located on chromosome $5 \mathrm{q} 33.2$ and consists of three members (TIM-1, 3 , and 4) [1]. Individual TIM family members may serve as susceptibility markers for asthma, allergies, and autoimmune diseases, as well as potential cell surface markers for $\mathrm{T}$ helper (Th) type 1 and Th2 cells $[1,2]$. Therefore, the human TIM gene family is critical in the regulation of Th1/Th2 mediated immunological reactions [2].

TIM-1 was first identified as a hepatitis A virus cellular receptor $1[3,4]$ and a kidney injury molecule, KIM-1 [5, 6]. TIM-1 is expressed on $\mathrm{CD} 4^{+} \mathrm{T}$ cells after activation and its expression is sustained preferentially in Th2 but not Th1 cells $[1,7]$. TIM-1 plays an important role regulating immune responses and the development of autoimmune disease. The high-avidity anti-Tim-1 antibody enhances the severity of experimental autoimmune encephalitis by increasing autopathogenic Th1 and Th17 responses, whereas the low-avidity antibody inhibits autopathogenic Th1 and Th17 responses [8].

TIM-4 is a natural ligand of TIM-1 [7] and is exclusively expressed on antigen-presenting cells, including dendritic cells (DCs) and macrophages $[9,10]$, where it mediates phagocytosis of apoptotic cells and plays an important role maintaining tolerance $[11,12]$. TIM-1 and TIM- 4 interact to regulate Th cell responses and modulate the Th1/Th2 cytokine balance [7]. DC-derived TIM-4 maintains TIM-1 in Th2 cells in a stable status and plays a critical role sustaining Th2 polarization [13]. TIM- 4 binding to TIM-1 has different effects on $\mathrm{T}$ cell proliferation. A higher dose of Tim-4-Ig consistently leads to an increase in $\mathrm{T}$ cell proliferation upon ligation with the T-cell receptor, whereas a lower concentration of Tim4-Ig inhibits T cell proliferation [7]. Human TIM-1 is also associated with other types of immune dysfunction, such as atopic dermatitis, allergy, rheumatoid arthritis, asthma, and 
systemic lupus erythematosus (SLE) [14-18], suggesting that Tim-1 may regulate immune responses. In addition, TIM-4 expression in peripheral blood mononuclear cells (PBMCs) also increases in patients with SLE [13].

Behçet's Disease (BD) is a Thl-polarized [19], chronic, multisystemic inflammatory disorder with arthritis, gastrointestinal, mucocutaneous, ocular, vascular, and central nervous system involvement. This disease takes a chronic course with periodic exacerbations and progressive deterioration [20]. The etiology of BD is unclear; however, viral infection has long been postulated as one of the main factors. Since Behçet first proposed a viral etiology [21], his hypothesis has been verified by detecting virus in saliva [22], intestinal ulcers [23], and genital ulcers [24, 25] of patients with BD. Subsequently, herpes simplex virus (HSV) inoculation of the earlobes of ICR mice resulted in the development of BD-like symptoms [26]. Manifestations in mice inoculated with HSV include multiple symptoms such as oral ulcers, genital ulcers, skin ulcers, eye symptoms, intestinal ulcers, arthritis, and neural involvement, as well as skin crusting. The frequencies of these symptoms are similar to those of patients with BD [27].

TIM-1 and TIM-4 have not been studied much in BD until now. In this study, we investigated the Tim expression in a BD mouse model with BD-like symptoms. The expression Tim- 1 and Tim- 4 was analyzed in BD mice and the changes in BD-like symptoms were observed by regulating of Tim-1 or Tim-4 expression. Furthermore, the changes in cellular phenotypes and cytokine levels on immune cells were confirmed after upregulation of Tim-1 or downregulation of Tim-4 in BD mice.

\section{Materials and Methods}

2.1. Antibodies and Reagents. Mouse anti-CD4, anti-Tim-1, anti-Tim-4, anti-CD8a, anti-CD122, anti-CD11b, anti-CD11c, and anti-CD25 antibodies as well as an anti-Foxp3 staining kit were purchased from eBioscience (San Diego, CA, USA).

2.2. Animal Experiments. ICR male mice (4-5 weeks old) were infected with HSV type $1\left(1 \times 10^{6} \mathrm{pfu} / \mathrm{mL}, \mathrm{F}\right.$ strain $)$ grown in Vero cells as described previously [26]. We used anesthetic composed of a mixture of Zoletil (Virbac Lab, Carros, France) and Rompun (Bayer, Seoul, Korea). The ratio of Zoletil and Rompun was 1:4, and it was administered at a dose of $40 \mu \mathrm{L} /$ mouse (tiletamine $10 \mathrm{mg} / \mathrm{kg}$, zolazepam $10 \mathrm{mg} / \mathrm{kg}$, and xylazine hydrochloride $36 \mathrm{mg} / \mathrm{kg}$ ) via intramuscular injection. Virus inoculation was conducted twice at 10 day intervals, after which the animals were observed for 16 weeks. Animals were handled in accordance with a protocol approved by the animal care committee of Ajou University School of Medicine (Institutional approved number: AMC102).

2.3. BD-Like Symptoms. Multiple symptoms were observed in the mice after HSV inoculation, and $12 \%$ of the HSVinjected mice developed BD-like symptoms. Disappearance of symptoms or a $>20 \%$ decrease in dimension of lesion size was classified as effective. Determination of the $\mathrm{BD}$ severity score was followed by determining the value of the $\mathrm{BD}$ activity index, as outlined on the BD activity form (http://www.behcet.ws/pdf/BehcetsDiseaseActivityForm .pdf). Symptoms exhibited by patients, including mouth ulceration, genital ulceration, erythema, skin pustules, skin ulceration, joints-arthritis, diarrhea, blurred or red eye (right, left), reduced vision (right, left), loss of balance, discoloration of skin, and swelling of the face were selected and analyzed in the BD mouse model. The score of each symptom was one, and the total score was used to determine the BD severity score.

2.4. Tim-1 DNA Constructs. A Tim-1 construct with an extracellular Flag epitope tag was generated [28]. A cDNA clone containing the entire coding sequence of murine Tim-1 was constructed. Briefly, the Tim-1 open reading frame (excluding the start codon and signal sequence) was amplified from this clone by polymerase chain reaction and ligated into a pCDEF3 expression plasmid [29]. All DNA constructs were verified by automated DNA sequencing. All plasmids used were purified by two passes through Endo-Free columns (Qiagen, Chatsworth, CA, USA) as described previously [30].

2.5. Preparation of Tim-4 Small Interfering RNA (siRNA). Tim-4 siRNA (siTim-4) was synthesized by Genolution Pharmaceuticals, Inc. (Seoul, Korea). The synthesized sequences of Tim-4 siRNA were sense: $5^{\prime}$ - CUA AAU CAC AUC AGA UCA ACA GCA GUU - $3^{\prime}$, and antisense: $5^{\prime}$ - CUG CUG UUG AUC UGA UGU GAU UUA GUU - $3^{\prime}$. The Tim-4 siRNA with transfection reagent jetPEI (PolyPlustransfection, Llkirch, France) was used to inject into mice.

2.6. Tim-1 Vector and Tim-4 siRNA Administration of BD Mice. Ten $\mu \mathrm{g}$ of Tim-1 vector was intraperitoneally injected four times at 2 day intervals into $\mathrm{BD}$ mice when the BD-like symptoms appeared, followed by 2 weeks of observations. The control was injected with the pCDEF3 empty vector. Five $\mu \mathrm{g}$ of siRNA Tim-4 was intraperitoneally injected three times at 2 day intervals into BD mice to downregulate Tim-4, followed by a 2 -week observation. Scrambled siRNA was used as the negative control (Genolution Pharmaceuticals, Inc., Seoul, Korea).

2.7. Flow Cytometry. PBMCs and lymph node cells were isolated from mice and erythrocytes were removed from cell suspensions in ACK solution, then washed with phosphate buffered saline (PBS). The cells were surface-stained with anti-mouse antibodies (CD4, CD8, CD11b, CD11c, CD25, CD122, Tim-1, and Tim-4) for $30 \mathrm{~min}$ at $4^{\circ} \mathrm{C}$ in the dark. An anti-mouse Foxp3-staining buffer set was used according to the manufacturer's instructions to detect Foxp3 intracellularly. Briefly, cells were fixed using Fix/perm buffer after washing with $1 \mathrm{x}$ permeabilization buffer and then incubated with anti-mouse Foxp3 antibody. For analysis, the cells were gated and then the population of stained cells was analyzed by a flow cytometer (FACS Canto II; Becton Dickinson, Franklin Lakes, NJ, USA) with $\geq 10,000$ gated lymphocytes. 
2.8. Enzyme Linked Immunosorbent Assay (ELISA). Serum was collected 14 days after the first administration of the Tim-1 vector and Tim- 4 siRNA into BD mice. Serum was analyzed using commercial ELISA kits for the detecting mouse interleukin (IL)-6 (R\&D Systems, Minneapolis, MN), tumor necrosis factor (TNF)- $\alpha$ (R\&D Systems), IL-17 (R\&D Systems), IL-4 (R\&D System), and interferon (IFN)- $\gamma$ (R\&D Systems), according to the manufacturer's instructions. The ELISA reader was Bio-Rad model 170-6850 microplate reader, and samples were read at a wavelength of $450 \mathrm{~nm}$.

2.9. Statistical Analysis. All data are expressed as mean \pm standard deviation. Statistical differences between the experimental groups were determined using Student's $t$-test with a Bonferroni correction. Statistical analysis was conducted using MedCalc version 9.3.0.0. A $P<0.05$ was considered significant.

\section{Results}

3.1. The Frequencies of Tim-1 and Tim-4 Expressing Cells in Normal Healthy, BD Normal (BDN), and BD Mice. The frequencies of Tim $-1^{+}, \mathrm{CD} 4^{+} \mathrm{Tim}-1^{+}$, and $\mathrm{CD} 8^{+} \mathrm{Tim}-1^{+}$cells were analyzed in cells from lymph nodes (LN), spleen (SP), and PBMCs of normal healthy (Nor) and BDN (HSV-1 was inoculated but no symptoms) mice and compared with those in BD mice by FACS. In LN, the frequencies of Tim$1^{+}, \mathrm{CD}^{+}{ }^{\mathrm{Tim}}-1^{+}$, and $\mathrm{CD} 8^{+} \mathrm{Tim}-1^{+}$cells in $\mathrm{BD}$ mice were significantly lower than those in $\mathrm{BDN}$ mice $(\mathrm{BDN}$ versus $\mathrm{BD}(\%):$ Tim $-1^{+}, 20.1 \pm 11.5(n=12)$ versus $11.1 \pm 6.7$ $(n=12), P=0.01 ; \mathrm{CD}^{+} \mathrm{Tim}^{-1}{ }^{+}, 3.4 \pm 1.9(n=9)$ versus $2.2 \pm 1.6(n=9), P=0.09 ; \mathrm{CD}^{+} \mathrm{Tim}^{-1}{ }^{+}, 1.9 \pm 1.1(n=9)$ versus $1.1 \pm 0.6(n=9), P=0.04)$ (Figure $1(\mathrm{a}))$. In SP, the BD mice showed significantly lower frequencies than Nor or BDN mice (Nor versus BDN versus BD (\%): Tim $-1^{+}, 21.3 \pm 6.5$ $(n=6)$ versus $18.3 \pm 8.5(n=10)$ versus $12.2 \pm 5.9(n=$ $10)$, Nor versus BD $P=0.006, \mathrm{BDN}$ versus $\mathrm{BD} P=0.04$; $\mathrm{CD} 4^{+} \mathrm{Tim}-1^{+}, 3.1 \pm 1.6(n=6)$ versus $1.9 \pm 1.0(n=8)$ versus $1.7 \pm 0.5(n=8)$, Nor versus $\mathrm{BD} P=0.02$, BDN versus $\mathrm{BD} P=0.35)$. CD $8^{+}$Tim $-1^{+}$cells showed similar frequencies among three groups (Figure 1(b)). In PBMCs, the frequencies of $\mathrm{BD}$ mice were slightly lower than those of $\mathrm{BDN}$, but not significantly (BDN $(n=9)$ versus $\mathrm{BD}(n=9)(\%)$ : Tim $-1^{+}$, $27.6 \pm 17.1$ versus $23.6 \pm 8.4, P=0.54 ; \mathrm{CD}^{+}{ }^{+} \mathrm{Tim}-1^{+}, 8.3 \pm 5.9$ versus $5.7 \pm 4.4, P=0.31$; $\mathrm{CD}^{+} \mathrm{Tim}^{-1}{ }^{+}, 7.6 \pm 5.0$ versus $5.2 \pm 4.3, P=0.29)$. BD mice had significantly higher levels than those of Nor mice (Figure 1(c)). These data indicate that the frequencies of Tim-1 expressing cells in $\mathrm{BD}$ mice were downregulated compared to those in BDN mice.

The frequencies of Tim $-4^{+}$cells were also analyzed in LN, SP, and PBMCs of Nor, BDN, and BD mice. In LN, the frequencies of Tim $-4^{+}$cells in $\mathrm{BD}$ mice were significantly higher than those in Nor and BDN mice (Nor versus BDN, versus $\mathrm{BD}(\%): 1.3 \pm 0.8(n=11)$ versus $3.2 \pm 0.9(n=15)$ versus $5.8 \pm 2.0(n=15)$, Nor versus BDN $P=0.000005$, Nor versus $\mathrm{BD}, P=0.0000001, \mathrm{BDN}$ versus $\mathrm{BD} P=0.00003$ ) (Figure $2(\mathrm{a})$ ). In SP, the frequencies of Tim $-4^{+}$cells in $\mathrm{BD}$ mice were also significantly higher than those in Nor mice
(Nor versus $\mathrm{BD}(\%): 3.9 \pm 2.8(n=11)$ versus $6.7 \pm 4.3$ ( $n=17), P=0.035)$. However, the difference between BDN and BD mice was not significant (Figure 2(b)). In PBMCs, the frequencies of Tim $-4^{+}$cells in $\mathrm{BD}$ mice were higher than those in Nor mice (Figure 2(c)). Moreover, in peritoneal macrophages, the frequencies of Tim $-4^{+}$cells in $\mathrm{BD}$ mice were significantly higher than those in Nor and BDN mice (Nor versus $\mathrm{BDN}$ versus $\mathrm{BD}(\%): 6.1 \pm 2.0(n=5)$ versus $8.6 \pm 4.0(n=9)$ versus $26.6 \pm 17.0(n=5)$, Nor versus $\mathrm{BDN}, P=0.11$, Nor versus $\mathrm{BD}, P=0.02$, $\mathrm{BDN}$ versus $\mathrm{BD}, P=0.005)$. No differences between Nor and BDN mice were observed (Figure $2(\mathrm{~d})$ ). In addition, we also examined

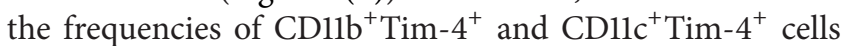
in $\mathrm{LN}$ and SP. In LN, both markers in BD mice were higher than those in Nor and BDN mice (Nor $(n=5)$ versus BDN

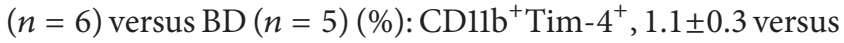
$1.7 \pm 0.7$ versus $3.0 \pm 1.4$, Nor versus $\mathrm{BDN}, P=0.05$, Nor

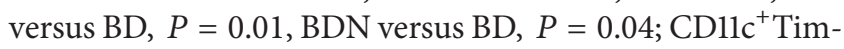
$4^{+}, 0.1 \pm 0.0$ versus $0.5 \pm 0.1$ versus $0.7 \pm 0.5$, nor versus $B D N$, $P=0.00003$, Nor versus $\mathrm{BD}, P=0.01, \mathrm{BDN}$ versus $\mathrm{BD}, P=$ 0.14 ) (Figure 2(e)). In splenocytes, expression of CD11c ${ }^{+} \mathrm{Tim}^{-}$ $4^{+}$cells was similar to that in LN in Nor $(0.3 \pm 0.1 \%, n=5)$, $\operatorname{BDN}(0.6 \pm 0.4 \%, n=6)$ and BD mice $(1.0 \pm 0.6 \%, n=8)$ (Nor versus $\mathrm{BDN}, P=0.07$, Nor versus $\mathrm{BD}, P=0.07$, $\mathrm{BDN}$ versus $\mathrm{BD}, P=0.1)$. In contrast, the frequencies of $\mathrm{CD}_{11 \mathrm{~b}}{ }^{+} \mathrm{Tim}-4^{+}$ cells in BD mice were significantly lower than those in Nor, but higher than those in BDN mice (Figure 2(f)). These data suggest that the frequencies of Tim- 4 expressing cells in $\mathrm{BD}$ mice were upregulated compared to those in BDN mice.

3.2. Administration of the Tim-1 Vector Upregulates the Frequencies of Tim- $1^{+}$Cells In In Vivo LN. We investigated the change in $\mathrm{BD}$-like symptoms according to the regulation of Tim-1 expression. The Tim-1 expression vector was administered to BD mice to upregulate Tim-1 expression. The Tim-1 vector was injected intraperitoneally at 10,30 , and $50 \mu \mathrm{g} /$ mouse into Nor mice twice at 2 day intervals. The frequencies of Tim $-1^{+}$cells from $\mathrm{LN}$ were compared to those of the control vector injected group the day after the last injection. The expression of Tim $-1^{+}$cells in the $10 \mu \mathrm{g}$ Tim-1 vector injected group $(19.1 \pm 5.1 \%, n=4)$ was significantly higher than that in the control vector injected group $(10 \mu \mathrm{g}$ : 9.4 $\pm 2.6 \%, n=4, P=0.01 ; 50 \mu \mathrm{g}: 10.4 \pm 5.4 \%, n=4, P=0.06)$ (Figure 3). However, the $30(n=3)$ and $50 \mu \mathrm{g}(n=4)$ Tim-1 vector injected groups showed lower expression than that in the $10 \mu \mathrm{g}$ injected group. Thus, $10 \mu \mathrm{g}$ of the Tim-1 vector was used for subsequent experiments.

3.3. Administration of Tim-1 Vector Affected BD-Like Symptoms. Ten $\mu \mathrm{g}$ of Tim-1 vector was injected intraperitoneally into BD mice four times at 2 day intervals, followed by observations for 2 weeks. Skin and genital ulcers improved after administering the Tim-1 vector when compared to those in the control vector-injected group (Figure 4(a)). Additionally, the severity score was $2.83 \pm 0.41$ before and $2.83 \pm 0.75$ at 1 week in the control vector group and $2.67 \pm 1.21$ at 2 weeks after the first injection of control vector $(n=6)$. The severity score in the Tim-1 vector group was $3.17 \pm 0.75$ before 

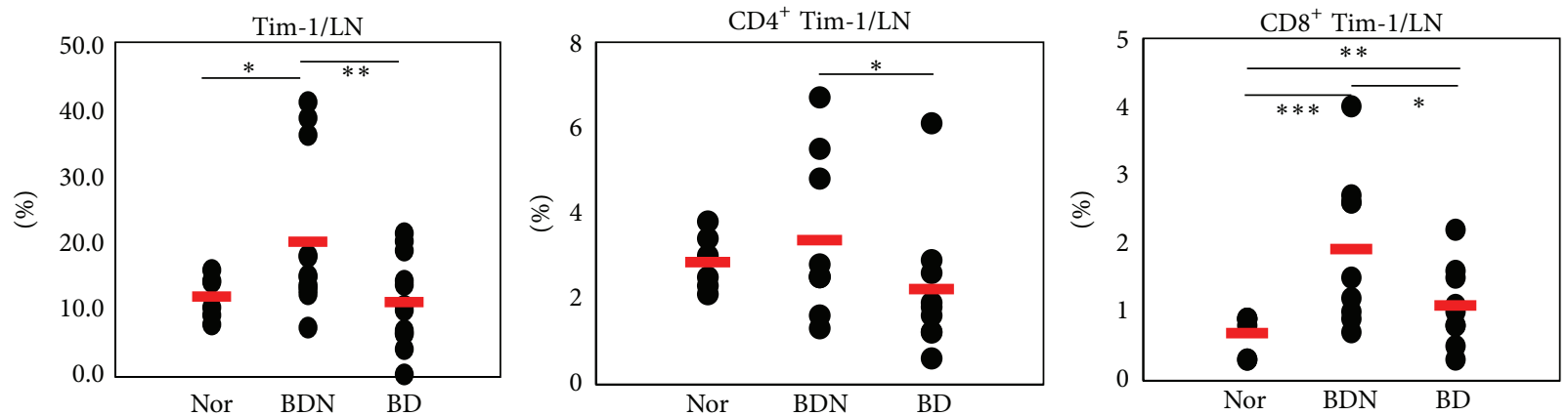

(a)
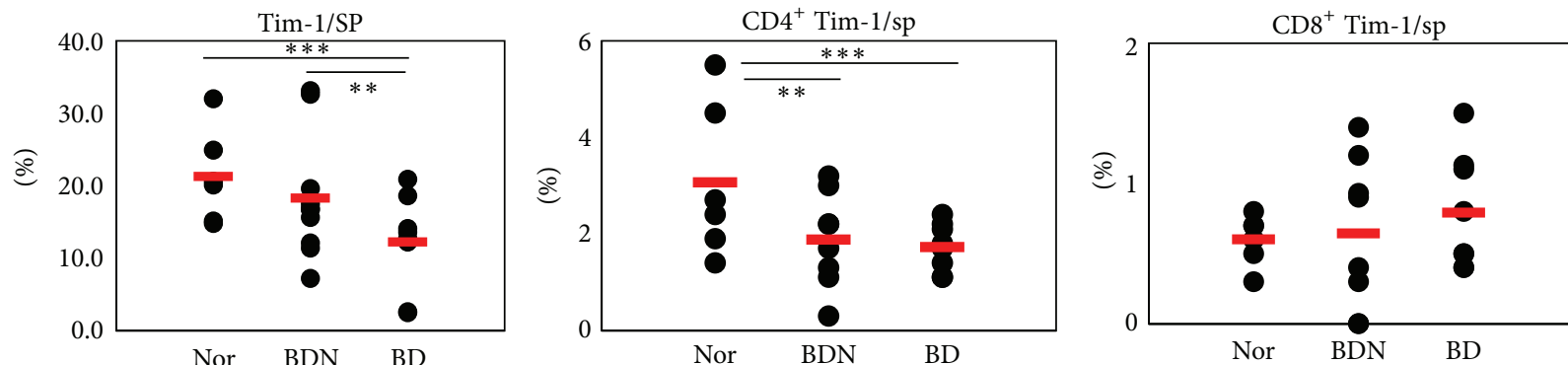

(b)
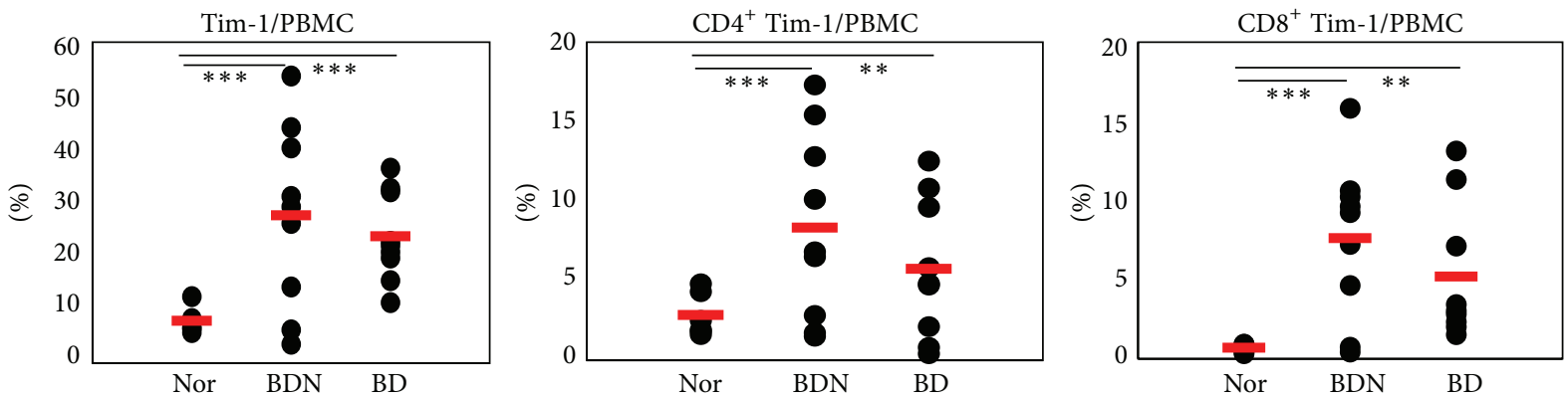

(c)

FIGURE 1: The frequencies of Tim- $1^{+}$cell phenotypes in normal healthy, Behçet's disease (BD) normal (BDN), and BD mice. The frequencies of Tim $-1^{+}, \mathrm{CD}^{+} \mathrm{Tim}_{-1} 1^{+}$and $\mathrm{CD} 8^{+} \mathrm{Tim}-1^{+}$, cells in BD mice were compared to Nor and BDN mice by FACS analysis in (a) lymph nodes, (b) spleen, and (c) peripheral blood mononuclear cells (PBMCs) $(n=6-12)\left({ }^{*} P<0.1,{ }^{* *} P<0.05,{ }^{* * *} P<0.01\right)$. Nor: normal healthy mice, BDN: BD normal mice.

injection, $1.50 \pm 1.22$ at 1 week after injection $(P=0.004)$, and $1.33 \pm 1.51$ at 2 weeks after injection in $\mathrm{BD}$ mice $(P=0.03, n=$ 6) (Figure 4(b)). The severity score decreased after injecting the Tim-1 vector, whereas the control vector injection did not result in a difference.

Two weeks after the first administration of the Tim-1 vector to $\mathrm{BD}$ mice, isolated $\mathrm{LN}$ and PBMCs were analyzed for Tim- $1^{+}$cells by FACS. In LN, the frequencies of Tim$1^{+}$cells in Tim-1 vector injected group were slightly higher compared to those in the control vector injected group (Con versus Tim-1 (\%): $10.3 \pm 1.7(n=4)$ versus $11.9 \pm 3.2(n=5)$, $P=0.19)$. However, $\mathrm{CD}^{+}{ }^{+} \mathrm{Tim}-1^{+}$and $\mathrm{CD} 8^{+} \mathrm{Tim}-1^{+}$cells were similar to those in the control vector injected group (Figure $4(\mathrm{c})$ ). The frequencies of Tim $-4^{+}$cells were also not different (Figure 4(d)). In PBMCs, Tim $-1^{+}$cells were slightly lower in the Tim-1 vector injected group, but $\mathrm{CD} 4^{+} \mathrm{Tim}-1^{+}$,
$\mathrm{CD} 8^{+} \mathrm{Tim}-1^{+}$, and Tim $-4^{+}$cells were not different (Figures 4(c)-4(d)). Interestingly, $\mathrm{CD}^{+}{ }^{+} \mathrm{T}$ cells in the Tim-1 vector injected group were slightly higher than those in the control vector injected group (Con versus Tim-1 (\%): $21.3 \pm 10.7$ $(n=8)$ versus $27.6 \pm 13.7(n=8), P=0.36)$ (Figure $4(\mathrm{c}))$.

3.4. Tim-1 Vector Administration Affects the Regulatory Cellular Phenotypes. Several cellular phenotypes in the LN and PBMCs were analyzed in $\mathrm{BD}$ mice after administering the Tim- 1 vector. The frequencies of $\mathrm{CD} 4^{+} \mathrm{CD} 25^{+}, \mathrm{CD} 4^{+} \mathrm{Foxp}^{+}$, and $\mathrm{CD}^{+}{ }^{+} \mathrm{CD} 25^{+}$Foxp $^{+}$(regulatory T, Treg) cells in LN were not significantly changed in the Tim-1 vector compared to those in the control vector injected group (Con $(n=5)$ versus Tim-1 $(n=6)(\%): \mathrm{CD}^{+} \mathrm{CD} 25^{+}, 6.5 \pm 1.6$ versus $6.1 \pm 2.3$, $P=0.35$; $\mathrm{CD}^{+}$Foxp3 $^{+}, 5.3 \pm 1.5$ versus $4.7 \pm 1.7, P=0.29$; Treg, $5.2 \pm 1.4$ versus $4.7 \pm 1.7, P=0.3$ ) (Figure 5(a)). But, 


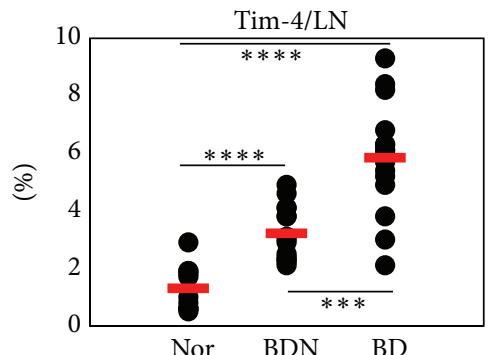

(a)

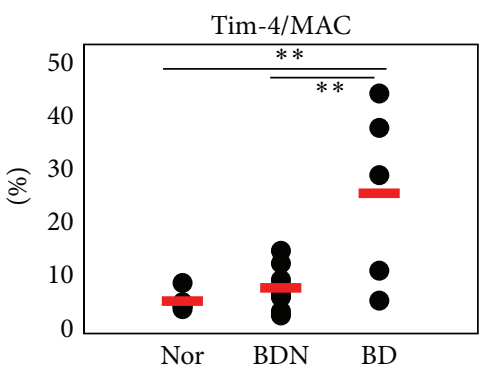

(d)

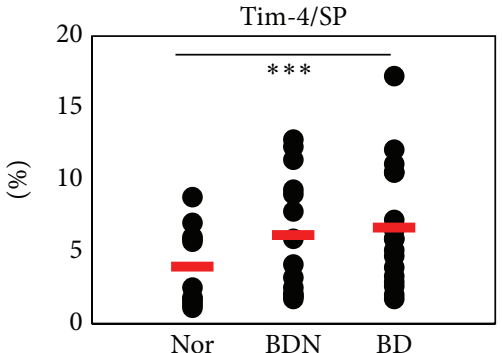

(b)

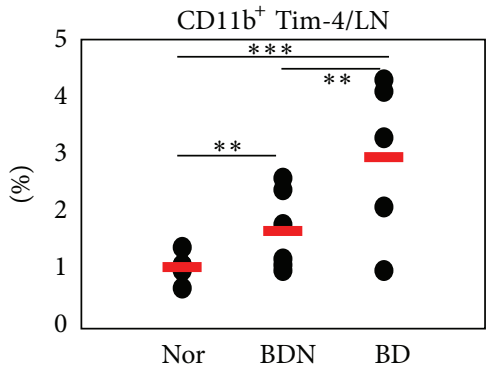

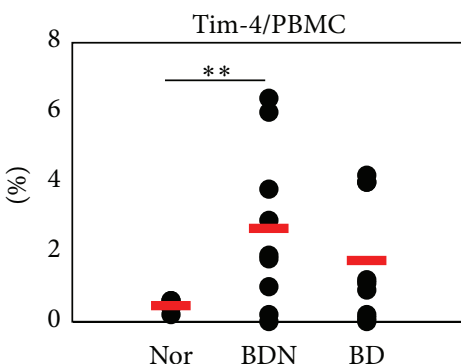

(c)

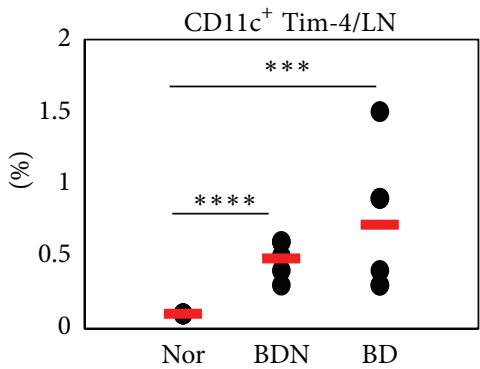

(e)
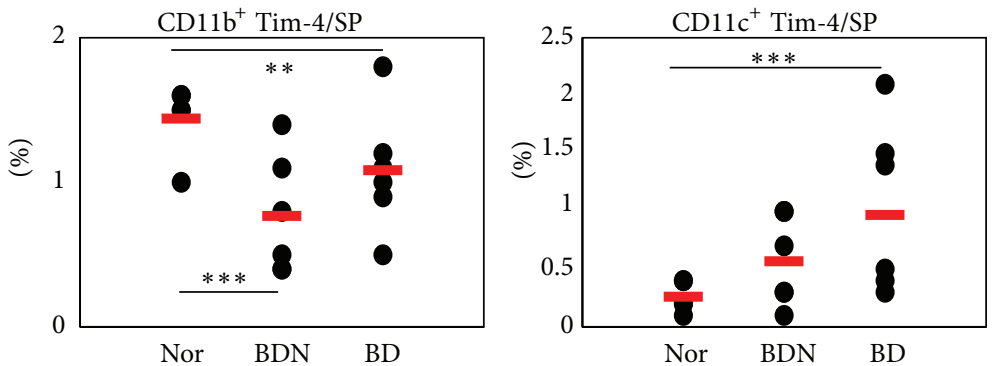

(f)

Figure 2: The frequencies of Tim $-4^{+}$cell phenotypes in normal healthy, BDN and Behçet's disease (BD) mice. The frequencies of Tim- $4^{+}$ cells in BD mice were compared to Nor and BDN mice by FACS analysis in (a) lymph nodes, (b) spleen, (c) PBMCs, and (d) peritoneal macrophages. The expression of $\mathrm{CD} 11 \mathrm{~b}^{+} \mathrm{Tim}-4^{+}$and $\mathrm{CD} 11 \mathrm{c}^{+} \mathrm{Tim}-4^{+}$cells in BD mice were also compared to those in Nor and BDN mice in (e) lymph nodes and (f) spleen $(n=5-17)\left({ }^{* *} P<0.05,{ }^{* * *} P<0.01,{ }^{* * * *} P<0.001\right)$ Nor: normal healthy mice, BDN: BD normal mice.

in PBMCs, $\mathrm{CD}^{+} \mathrm{CD} 25^{+}, \mathrm{CD}^{+}{ }^{+} \mathrm{Foxp}^{+}$, and Treg cells in the Tim-1 vector injected group were significantly higher than those in the control vector injected group (Con $(n=8)$ versus Tim-1 $(n=8)(\%)$ : $\mathrm{CD}^{+} \mathrm{CD}^{+} 5^{+}, 0.31 \pm 0.18$ versus $0.61 \pm 0.21$, $P=0.01 ; \mathrm{CD}^{+} \mathrm{Foxp}^{+}, 0.10 \pm 0.10$ versus $0.31 \pm 0.12$, $P=0.004$; Treg, $0.04 \pm 0.08$ versus $0.16 \pm 0.10, P=0.03$ ) (Figure 5(a)).

$\mathrm{CD}^{+} \mathrm{CD} 122^{+} \mathrm{T}$ cells are newly identified, regarded as Treg cells [31], and are involved in anti-inflammatory responses [32]. Another type of Treg cells, $\mathrm{CD}^{+} \mathrm{CD} 122^{+} \mathrm{T}$ cells, were also analyzed in LN of the Tim-1 vector injected group (Con $(n=5)$ versus Tim-1 $(n=6)(\%): 1.3 \pm 0.3$ versus $1.6 \pm 0.7, P=0.25$ ) (Figure 5(b)). In PBMCs, CD122 ${ }^{+}$and $\mathrm{CD}^{+}{ }^{+} \mathrm{CD} 122^{+} \mathrm{T}$ cells in the Tim-1 vector injected group were also higher than those in the control vector injected group (Con $(n=8)$ versus Tim-1 $(n=8)(\%)$ : CD122 $2^{+}, 1.2 \pm 1.0$ versus $9.8 \pm 7.9, P=0.04 ; \mathrm{CD}^{+} \mathrm{CD} 122^{+}, 1.9 \pm 1.5$ versus $2.4 \pm 2.1, P=0.58)$.
Our study indicated that the Tim-1 vector upregulated Treg cells and $\mathrm{CD}_{12} 2^{+}$cells in $\mathrm{BD}$ mice. Up-regulation of these cellular phenotypes may be involved in improved BDlike symptoms after injection of the Tim-1 vector.

3.5. Proinflammatory Cytokines are Downregulated by Tim1 Vector Administration in BD Mice. Sera were analyzed by ELISA at 2 weeks after Tim-1 vector administration into BD mice to determine the levels of cytokines. The IL-17 level in Tim-1 vector injected group was significantly lower than that in the control group (Con $(n=7)$ versus Tim-1 $(n=7)$ $(\mathrm{pg} / \mathrm{mL}): 11.53 \pm 4.45$ versus $6.84 \pm 2.17, P=0.03)$. TNF- $\alpha$ also decreased significantly in the Tim-1 vector injected group compared to that in the control group (Con $(n=11)$ versus Tim-1 $(n=11)(\mathrm{pg} / \mathrm{mL}): 16.5 \pm 13.8$ versus $6.9 \pm 5.1, P=0.04)$. The IL-6 level in the Tim-1 vector injected group decreased (Con $(n=8)$ versus Tim-1 $(n=8)(\mathrm{pg} / \mathrm{mL}): 145.7 \pm 176.9$ versus $72.2 \pm 38.8, P=0.27)$. In contrast, IL-4 increased 


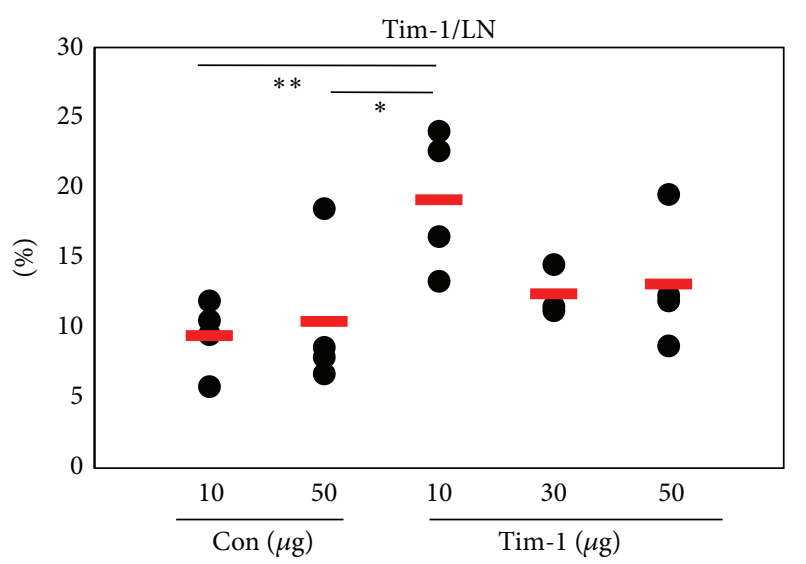

FIgURE 3: Administration of Tim-1 vector increased the frequencies of Tim- $1^{+}$cells. The Tim-1 vector was injected intraperitoneally at 10,30 , and $50 \mu \mathrm{g} / \mathrm{mouse}$ into Nor mice twice at 2 day intervals to observe up-regulation of Tim-1 expression. The day of the last injection, the frequencies of Tim- $1^{+}$cells in LN were compared to the control vector injected group by FACS analysis. The control was injected with the pCDEF3 empty vector (10 or $50 \mu \mathrm{g} / \mathrm{mouse})(n=3$ 4) $\left({ }^{* *} P<0.05\right)$. Con: control vector injection to normal (Nor) mice, Tim-1: Tim-1 vector injection to Nor mice.

slightly in the Tim-1 vector injected group (Con $(n=8)$ versus Tim-1 $(n=9)(\mathrm{pg} / \mathrm{mL}): 9.3 \pm 5.4$ versus $10.8 \pm 5.0, P=$ $0.53)$. But, IFN- $\gamma$ levels did not differ between the Tim-1 and control vector injected group (Figure 6). Consequently, these results indicate that the Tim-1 vector might downregulate proinflammatory cytokines in BD mice.

3.6. Tim-4 siRNA Treatment Downregulated the Expression of Tim-4 in Normal Healthy Mice. In BD mice, the frequencies of Tim $-4^{+}$cells were higher than those in Nor and BDN mice in LN cells and peritoneal macrophages (Figure 2). siTim-4 was injected into Nor mice intraperitoneally to downregulate Tim $-4^{+}$cells, and the frequencies of Tim $-4^{+}$cells were analyzed in peritoneal macrophages by FACS. Tim- 4 siRNA (siTim-4) at 2,5 , or $10 \mu \mathrm{g} /$ mouse or negative control (NC) scrambled siRNA (2 and $5 \mu \mathrm{g} /$ mouse) was injected (NC: $5 \mu \mathrm{g}$ versus siTim- $4-2,5$, and $10 \mu \mathrm{g}(n=4): 8.9 \pm 1.4 \%$ versus $6.6 \pm$ $3.4 \%(P=0.42), 3.7 \pm 0.9 \%(P=0.013), 2.8 \pm 2.2 \%(P=0.04))$ (Figure $7(\mathrm{a})$ ). siTim-4 downregulated Tim- $4^{+}$macrophages dose dependently and showed a significant difference in the $5 \mu \mathrm{g}$ and $10 \mu \mathrm{g}$ administered groups. Therefore, $5 \mu \mathrm{g}$ injections were used for the following experiment. To determine the time-dependent efficacy of Tim- 4 siRNA, $5 \mu \mathrm{g}$ of siTim- 4 was injected, and the frequencies of Tim $-4^{+}$macrophages were analyzed by FACS after 24, 48, and 72 hours. siTim4 significantly downregulated Tim $-4^{+}$macrophages until 72 hours compared to that of NC. The frequencies of Tim $-4^{+}$ at 48 hours were lowest (NC versus siTim- $4(n=2): 24 \mathrm{~h}$, $7.9 \pm 0.6 \%$ versus $4.9 \pm 0.2 \%, P=0.02 ; 48 \mathrm{~h}, 8.9 \pm 1.4 \%$ versus $2.9 \pm 0.4 \%, P=0.03 ; 72 \mathrm{~h}, 15.4 \pm 0.1 \%$ versus $4.2 \pm 3.0 \%$, $P=0.03$ ) (Figure 7(b)).

3.7. Administration of siTim-4 Changes BD-Like Symptoms. Five $\mu \mathrm{g}$ of siTim-4 was injected intraperitoneally three times at 2 day intervals into BD mice and the mice were observed for 2 weeks (Figure 8(a)). After administration of siTim-4, BD-like symptoms, such as skin and genital ulcers, were compared to the control group. In the negative control group, the severity score was $2.25 \pm 0.46$ before, $2.00 \pm 1.07$ at one week $(P=0.35)$, and $1.88 \pm 1.13$ at 2 weeks after the first injection of $\mathrm{BD}$ mice $(P=0.28, n=8)$. In the siTim- 4 treated group, the score was $2.63 \pm 0.52$ before, $1.25 \pm 0.81$ at 1 week $(P=0.001)$, and $1.25 \pm 0.89$ at 2 weeks after injection into $\mathrm{BD}$ mice $(P=0.001, n=8)$ (Figure $8(\mathrm{~b}))$. At 1 and 2 weeks after the first administration of siTim- 4 to BD mice, macrophages were isolated from the peritoneal cavity and analyzed for Tim- 4 by FACS. The frequencies of Tim $-4^{+}$cells at 1 and 2 weeks after siTim- 4 treatment tended to be lower than those in the negative control group, but the difference was not significant ( 1 week: $18.6 \pm 4.8 \%$ versus $15.7 \pm 3.7 \%$, $P=0.31,2$ weeks: $20.7 \pm 6.5 \%$ versus $18.8 \pm 3.3 \%, P=$ 0.42) (Figure 8(b)). However, in LN, Tim $-4^{+}, \mathrm{CD}_{11 b^{+}}$Tim$4^{+}, \mathrm{CD} 11 \mathrm{c}^{+} \mathrm{Tim}-4^{+}, \mathrm{Tim}-1^{+}, \mathrm{CD} 4^{+} \mathrm{Tim}-1^{+}$, and $\mathrm{CD} 8^{+} \mathrm{Tim}-1^{+}$ cells in the siTim- 4 treated group were similar to those in the control treated group at 1 week after the first siTim- 4 injection (Figures 8(c)-8(d)). Even at 2 weeks after the first injection, those markers were not different (data not shown). In these results, BD-like symptoms improved with siTim-4 treatment and decreased the severity score.

3.8. Treg Cells are Upregulated in siTim-4 Treated BD Mice. The frequencies of $\mathrm{CD} 4^{+} \mathrm{CD} 25^{+}, \mathrm{CD} 4^{+} \mathrm{Foxp} 3^{+}$, and Treg $\left(\mathrm{CD} 4^{+} \mathrm{CD} 25^{+}\right.$Foxp $\left.^{+}\right)$cells were analyzed by FACS at 1 and 2 weeks after the first treatment with siTim-4 in BD mice (Figure 9). After 1 week, Treg cells increased slightly in siTim4 treated $\mathrm{BD}$ mice compared with those in the $\mathrm{NC}$ treated group (NC versus siTim-4: $\mathrm{CD} 4^{+} \mathrm{CD} 25^{+}, 5.82 \pm 2.01 \%$ versus $6.84 \pm 2.03 \%, P=0.45, n=5$; $\mathrm{CD}^{+} \mathrm{Foxp}^{+}, 4.64 \pm 1.9 \%$ versus $5.82 \pm 2.4 \%, P=0.41, n=5$; Treg, $3.28 \pm 1.57 \%$ versus $4.08 \pm 1.73 \%, P=0.47, n=5)$. After 2 weeks, Treg cells were significantly higher in siTim-4 treated BD mice than those in the NC treated group (NC versus siTim-4: $\mathrm{CD} 4^{+} \mathrm{CD} 25^{+}$, $4.8 \pm 0.6 \%$ versus $5.9 \pm 1.2 \%, P=0.03, n=6 ; \mathrm{CD}^{+} \mathrm{Foxp}^{+}$, $4.1 \pm 0.7 \%$ versus $5.2 \pm 1.2 \%, P=0.03, n=7$; Treg, $2.7 \pm 0.5 \%$ versus $3.5 \pm 0.9 \%, P=0.04, n=7)$. These results suggest that the increased number of Treg cells is associated with knock down of Tim-4 in BD mice.

3.9. Treatment with siTim-4 Decreases Serum Levels of IL-17 in BD Mice. After administering siTim-4 to BD mice, the serum level of IL-17 was analyzed by ELISA and compared with NC siRNA treated BD mice. The level of IL-17 tended to decrease in the siTim-4 treated group compared to that in the NC treated group, but the difference was not significant (NC versus siTim-4 $(n=8): 19.4 \pm 11.5 \mathrm{pg} / \mathrm{mL}$ versus $15.6 \pm$ $8.1 \mathrm{pg} / \mathrm{mL}, P=0.25$ ) (Figure 10).

\section{Discussion}

BD mice downregulated Tim-1 levels and upregulated Tim-4 levels in LN, SP, PBMCs, and peritoneal macrophages compared to those in $\mathrm{BDN}$ mice. Administration of the 

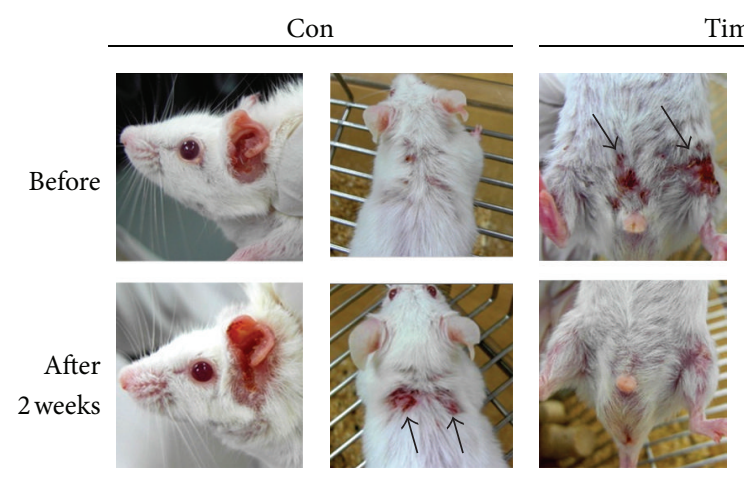

(a)
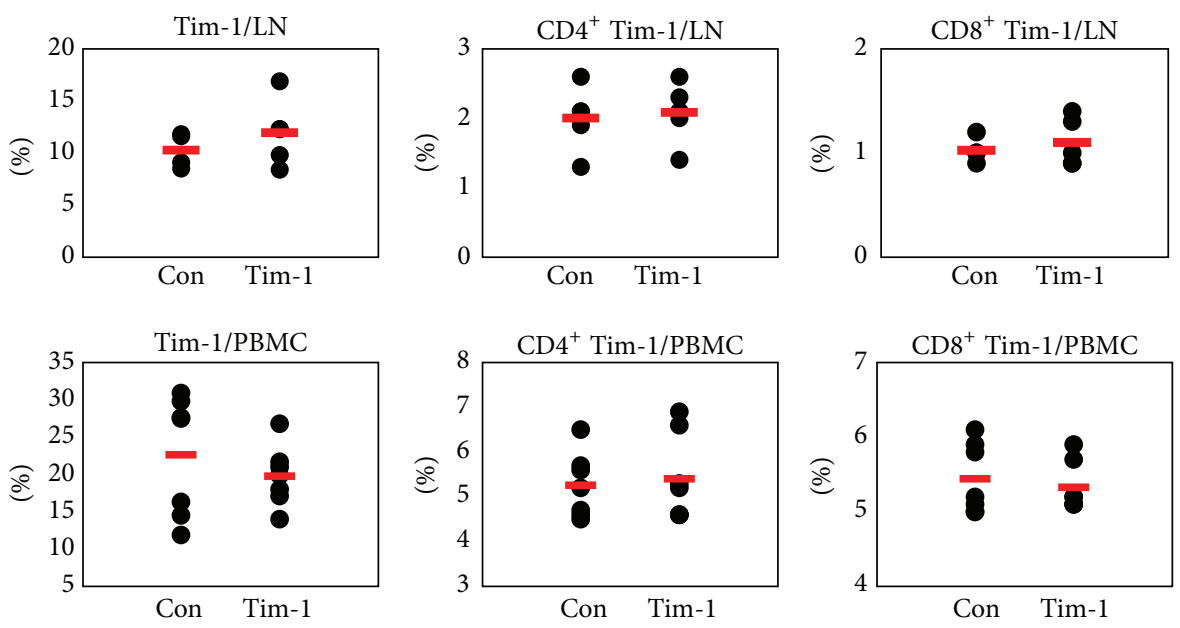

(c)
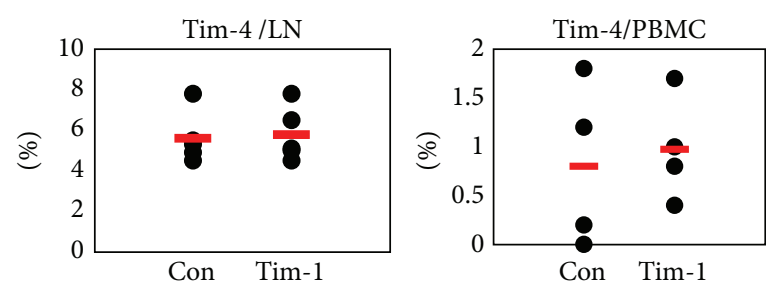

(d)
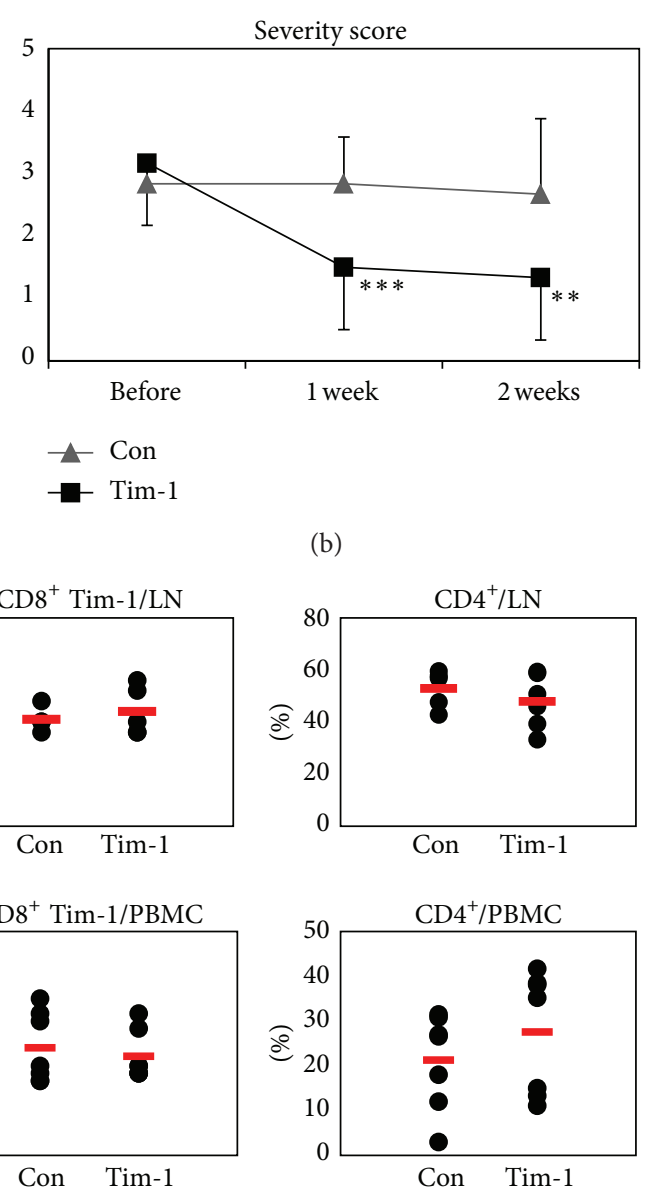

(b)$$
\text { (1) }
$$

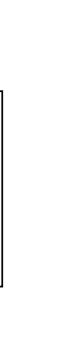

FIGURE 4: Administration of Tim-1 improved the Behçet's disease (BD)-like symptoms, but the frequencies of Tim-1 expressing cells remained unchanged. Ten $\mu \mathrm{g} /$ mouse of Tim-1 vector was injected intraperitoneally four times at 2 day intervals into BD mice, followed by 2 weeks of observations. (a) Photographs of mice were taken before and at 1 and 2 weeks after the first treatment of the Tim- 1 vector and control vector injected groups. (b) Severity scores were compared before and at 1 and 2 weeks after treatment. (c) Two weeks after first Tim- 1 vector injection, the frequencies of Tim $-1^{+}, \mathrm{CD} 4^{+} \mathrm{Tim}-1^{+}, \mathrm{CD} 8^{+} \mathrm{Tim}-1^{+}, \mathrm{CD} 4^{+} \mathrm{T}$ cells, and (d) Tim- $4^{+}$cells in LN and PBMCs were evaluated by FACS analysis $(n=5-6)\left({ }^{*} P<0.1\right)$. Con: control vector injection to BD mice, Tim-1: Tim-1 vector injection to BD mice.

Tim-1 vector upregulated the frequencies of Tim- $1^{+}$cells, and Tim- 4 siRNA downregulated the frequencies of Tim $-4^{+}$ cells. Administering the Tim-1 vector improved BD-like symptoms, such as genital and skin ulcers, and decreased the severity score. TIM-1 expression is lower in patients with active SLE compared to that in inactive patients [18]. Human TIM-1 is associated with immune dysfunction, such as atopic dermatitis, allergy, rheumatoid arthritis, asthma, and SLE [14-18]. Our data indicate that the Tim-1 related T cells phenotype did not change much after administering the Tim-1 vector. Interestingly, the frequencies of $\mathrm{CD}^{+}{ }^{\mathrm{T}}$ cells in PBMCs increased in the Tim-1 vector injected group compared to those in the control vector injected group. Actually, TIM-1 is expressed on CD $4^{+} \mathrm{T}$ cells after activation and its expression is preferentially sustained on Th2 but not Th1 cells $[1,7]$. Xiao et al. reported that Tim-1-Fc triggers a significant increase in the frequencies of $\mathrm{CD}^{+} \mathrm{T}$ cells [33]. In our study, Treg cells were upregulated in the 

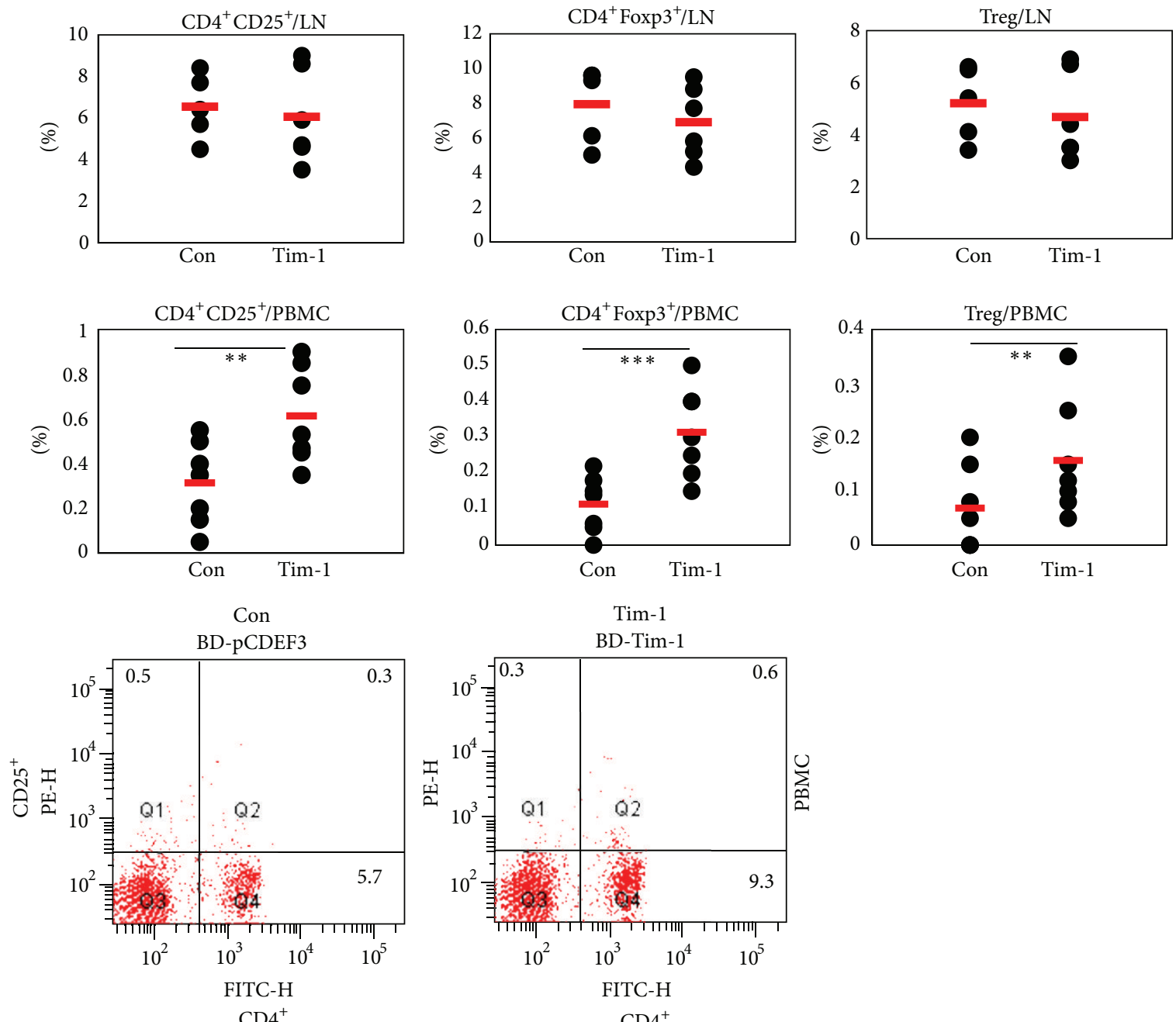

Tim-1

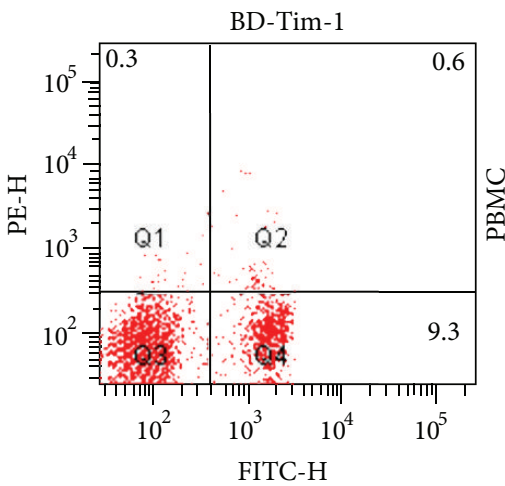

$\mathrm{CD} 4^{+}$

(a)
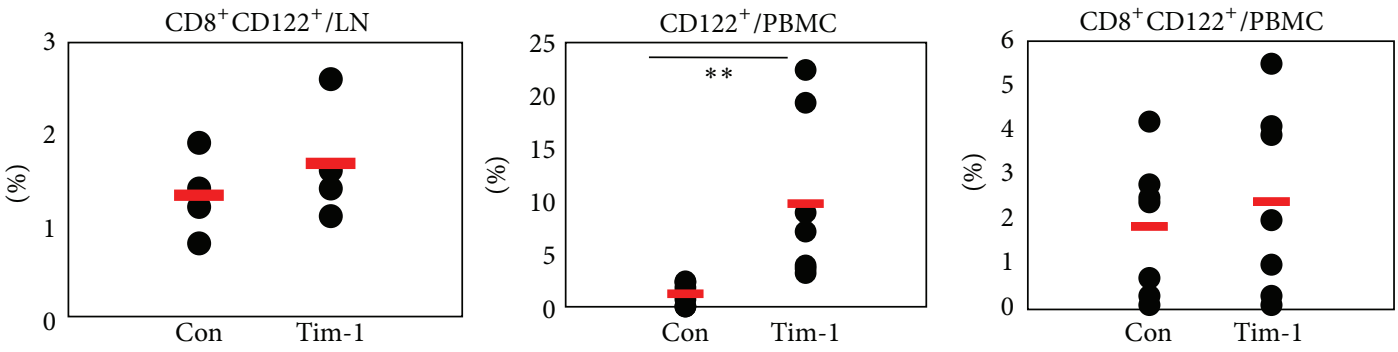

(b)

FIGURE 5: The frequencies of Treg cells in PBMCs were affected in Tim-1 vector injected Behçet's disease (BD) mice. Two types of Treg cells were confirmed in LN and PBMCs after Tim- 1 administration to BD mice. (a) The frequencies of CD $4^{+} \mathrm{CD} 25^{+}, \mathrm{CD} 4^{+}$Foxp $3^{+}$, and Treg cells were compared between the control and Tim- 1 vector injected groups. Bottom panel shows $\mathrm{CD} 4^{+} \mathrm{CD} 25^{+}$in PBMCs by FACS. (b) CD8 ${ }^{+} \mathrm{CD} 122^{+}$ $\mathrm{T}$ cells tended to be upregulated compared to those in the control group, but the difference was not significant. CD122 $2^{+}$cells increased significantly in the Tim-1 vector injected group $(n=5-8)\left({ }^{* *} P<0.05,{ }^{* * *} P<0.01\right)$. Con: control vector injection to BD mice, Tim-1: Tim-1 vector injection to $\mathrm{BD}$ mice.

Tim-1 vector injected BD group. Other Treg cells, $\mathrm{CD}^{+} \mathrm{CD}_{122^{+}} \mathrm{T}$ cells, were also higher in PBMCs and LN of the Tim-1 vector injected group compared to those in the control group. $\mathrm{CD}^{+} \mathrm{CD} 122^{+} \mathrm{T}$ cells are newly identified and regarded as Treg cells [31] and have an effect on antiinflammatory responses [32]. Our results suggest that the function of Tim-1 influenced the BD-like symptoms and is associated with Treg and $\mathrm{CD} 8^{+} \mathrm{CD} 122^{+} \mathrm{T}$ cells. 

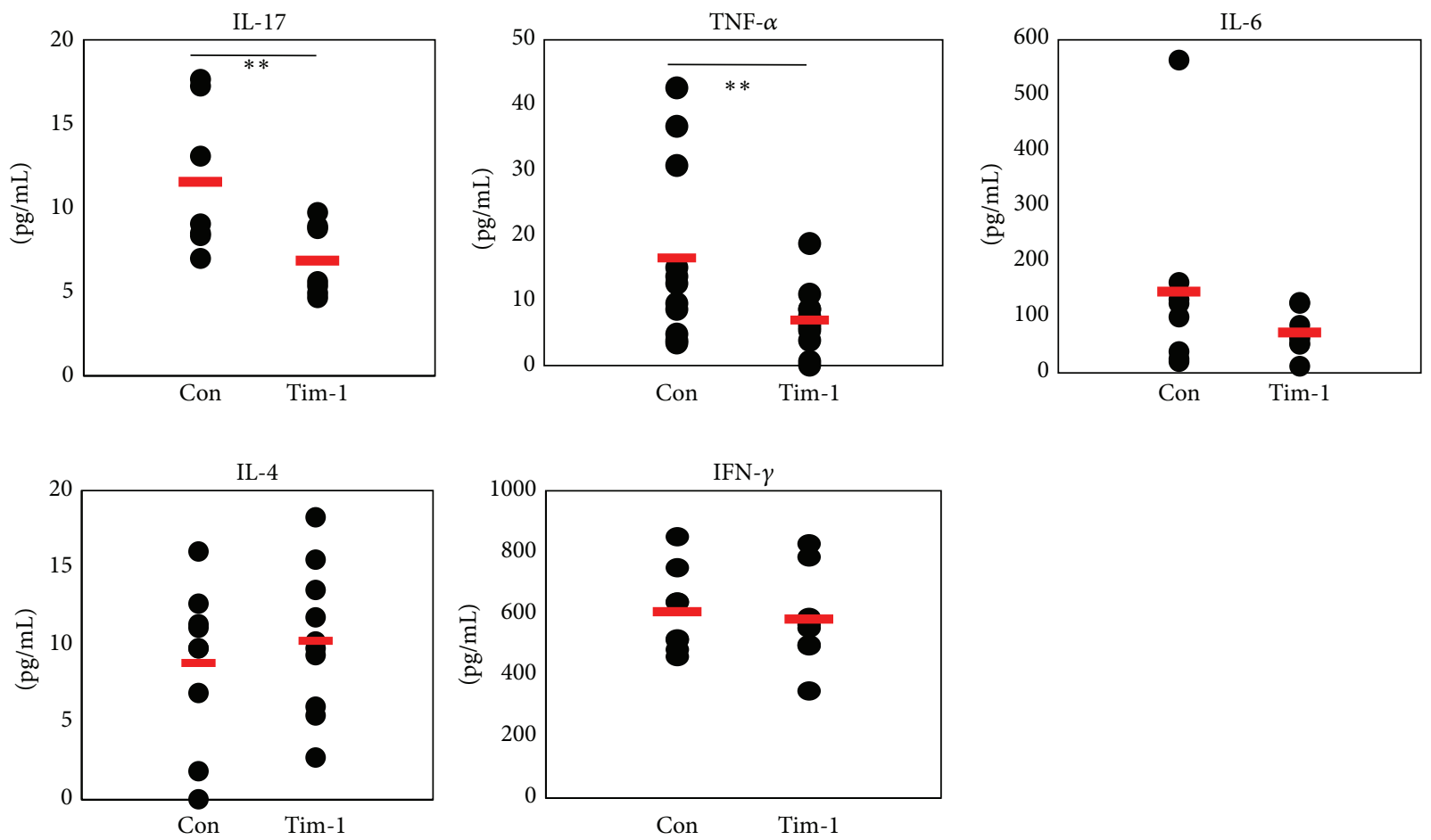

FIGURE 6: Administration of the Tim-1 vector decreased proinflammatory cytokines in Behçet's disease (BD) mice. Serum was isolated from blood at 2 weeks after the first injection of the Tim- 1 vector. The levels of interleukin (IL)-17, tumor necrosis factor (TNF)- $\alpha$, IL-6, interferon (IFN) $-\gamma$, and IL- 4 were analyzed in the sera of Tim- 1 and control vector injected BD mice by ELISA $(n=7 \sim 11)\left({ }^{* *} P<0.05\right)$. Con: control vector injection to BD mice, Tim-1: Tim-1 vector injection to BD mice.

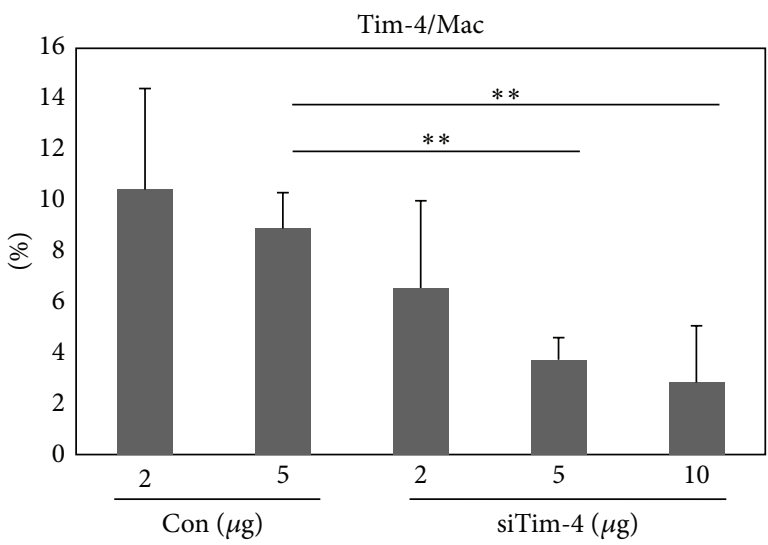

(a)

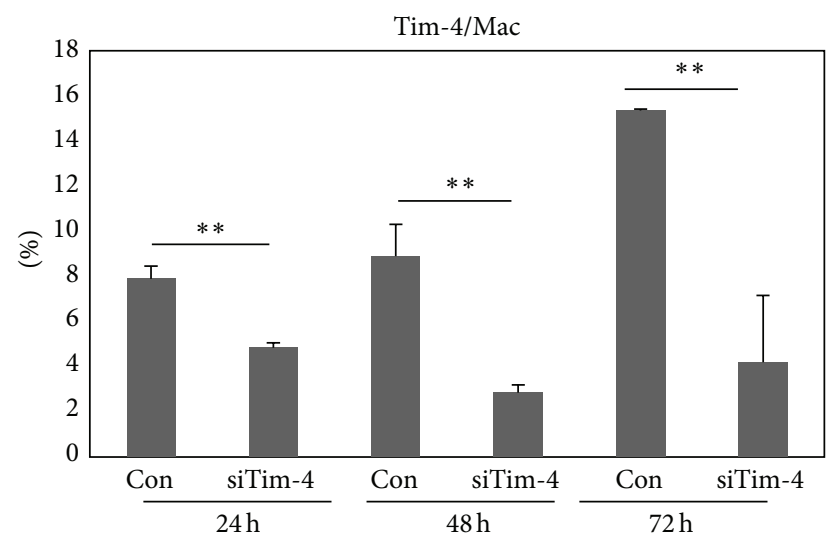

(b)

FIGURE 7: The expression of Tim $-4^{+}$cells was downregulated after siTim- 4 treatment. Tim- 4 siRNA was administered intraperitoneally and the frequencies of Tim $-4^{+}$cells were analyzed in peritoneal macrophages in normal (Nor) mice by FACS. (a) siTim- 42,5 , and $10 \mu \mathrm{g} / \mathrm{mouse}$ or negative control siRNA (Con) ( 2 and $5 \mu \mathrm{g}$ /mouse) were injected intraperitoneally into Nor mice. (b) Five $\mu \mathrm{g}$ of siTim- 4 was injected, and the frequencies of Tim $-4^{+}$peritoneal macrophages were analyzed 24, 48, and 72 hours later. Scrambled siRNA was used as the negative control $(n=3-4)\left({ }^{* *} P<0.05\right)$. Con: control siRNA injection into normal mice, siTim-4: Tim-4 siRNA injection to normal mice, Mac: peritoneal macrophage.

Recent studies suggest that IL-17 may play a dominant role in provoking chronic autoimmune inflammation and is considered essential for $\mathrm{T}$ cell-mediated colitis and promotion of inflammation [34-36]. The association of IL17 and IL-22 was also reported in patients with BD [37,
38]. TNF- $\alpha$ overexpression has been implicated in acute and chronic inflammatory diseases, such as septic shock, bowel disease, Crohn's disease, rheumatoid arthritis, atopic dermatitis, psoriasis, and BD [39]. Overproduction of IL6 plays a role in rheumatoid arthritis, juvenile idiopathic 


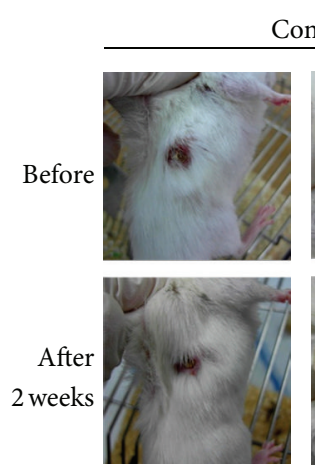

Con
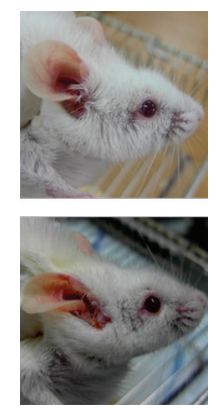

(a)

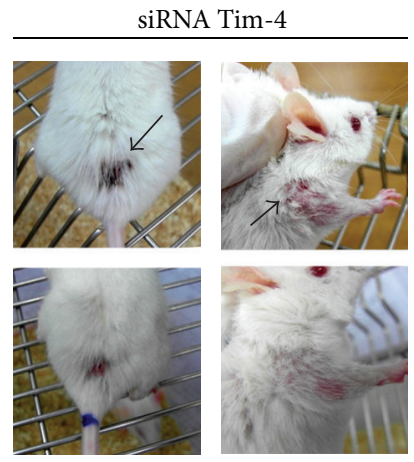

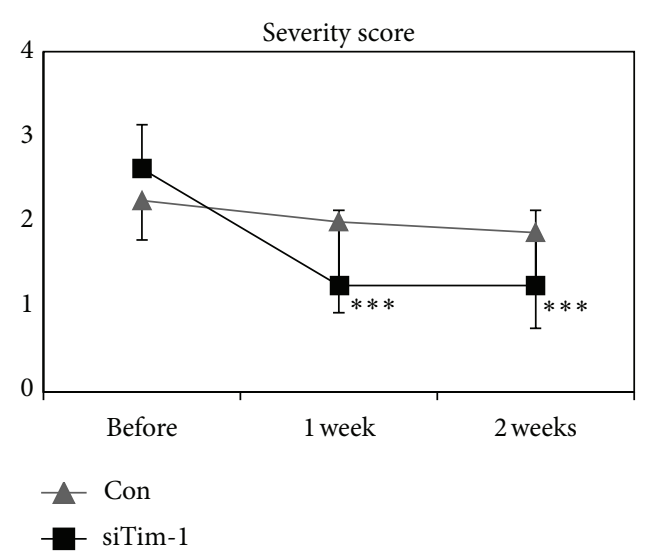

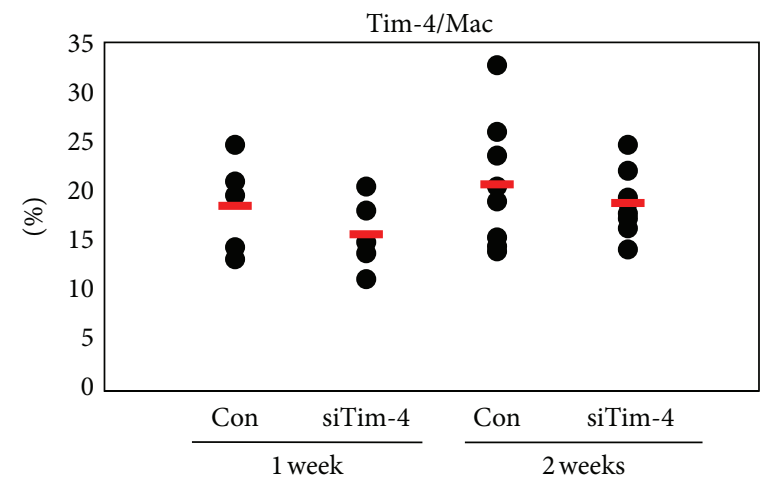

(b)
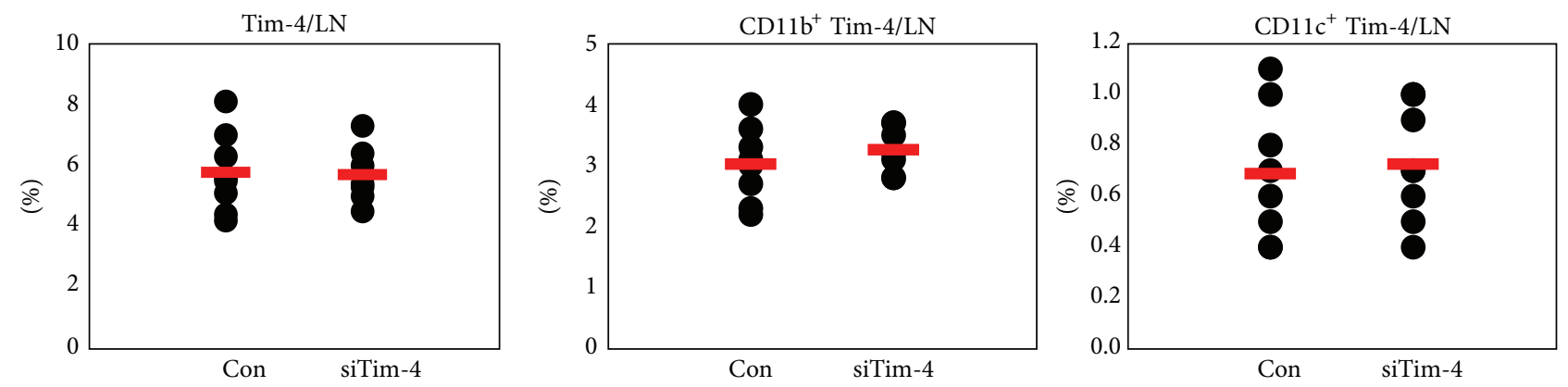

(c)
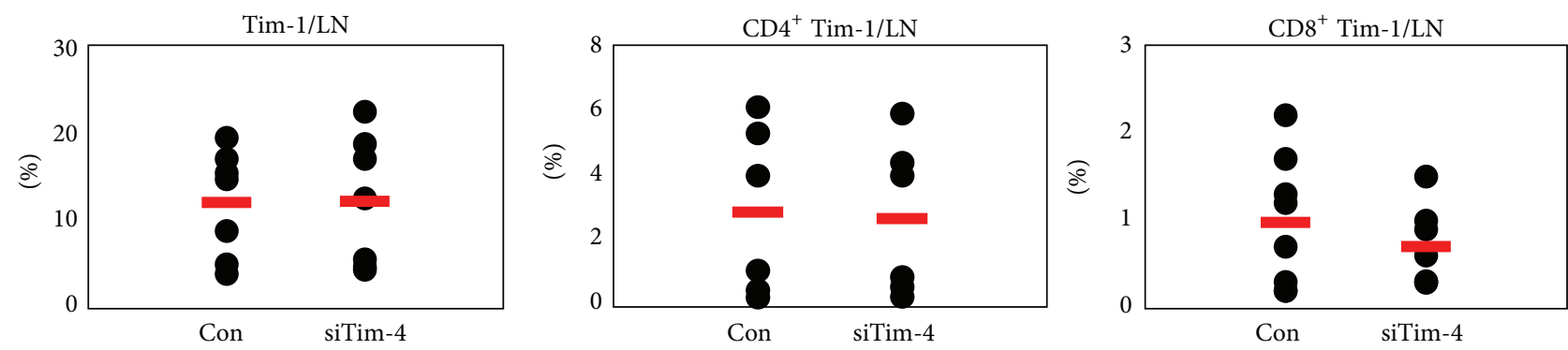

(d)

FIGURE 8: Behçet's disease (BD)-like symptoms were changed after siTim-4 administration. Five $\mu \mathrm{g} / \mathrm{mouse}$ of Tim- 4 siRNA was injected intraperitoneally three times at 2 day intervals into BD mice and they were observed for 2 weeks. (a) Photographs of mice taken before and at 1 and 2 weeks after treatment with siTim- 4 and the control treated group (Con: negative control siRNA treated groups). (b) The severity score was compared before and at 1 and 2 weeks after treatment between the siTim- 4 and control treated groups. The frequencies of Tim- $4^{+}$ cells in peritoneal cavity were compared between the siTim- 4 and control treated groups. (c, d) The frequencies of Tim- $4^{+}, \mathrm{CD}_{11 \mathrm{~b}}{ }^{+} \mathrm{Tim}-$ $4^{+}, \mathrm{CD} 11 \mathrm{c}^{+} \mathrm{Tim}-4^{+}, \mathrm{Tim}-1^{+}, \mathrm{CD} 4^{+} \mathrm{Tim}-1^{+}$, and $\mathrm{CD} 8^{+} \mathrm{Tim}-1^{+}$cells in $\mathrm{LN}$ were compared to the siTim- 4 and control treated groups $(n=7-8)$ $\left({ }^{* *} P<0.05\right)$. Con: negative control injection to BD mice, siTim-4: Tim-4 siRNA injection to BD mice, LN: lymph node. 

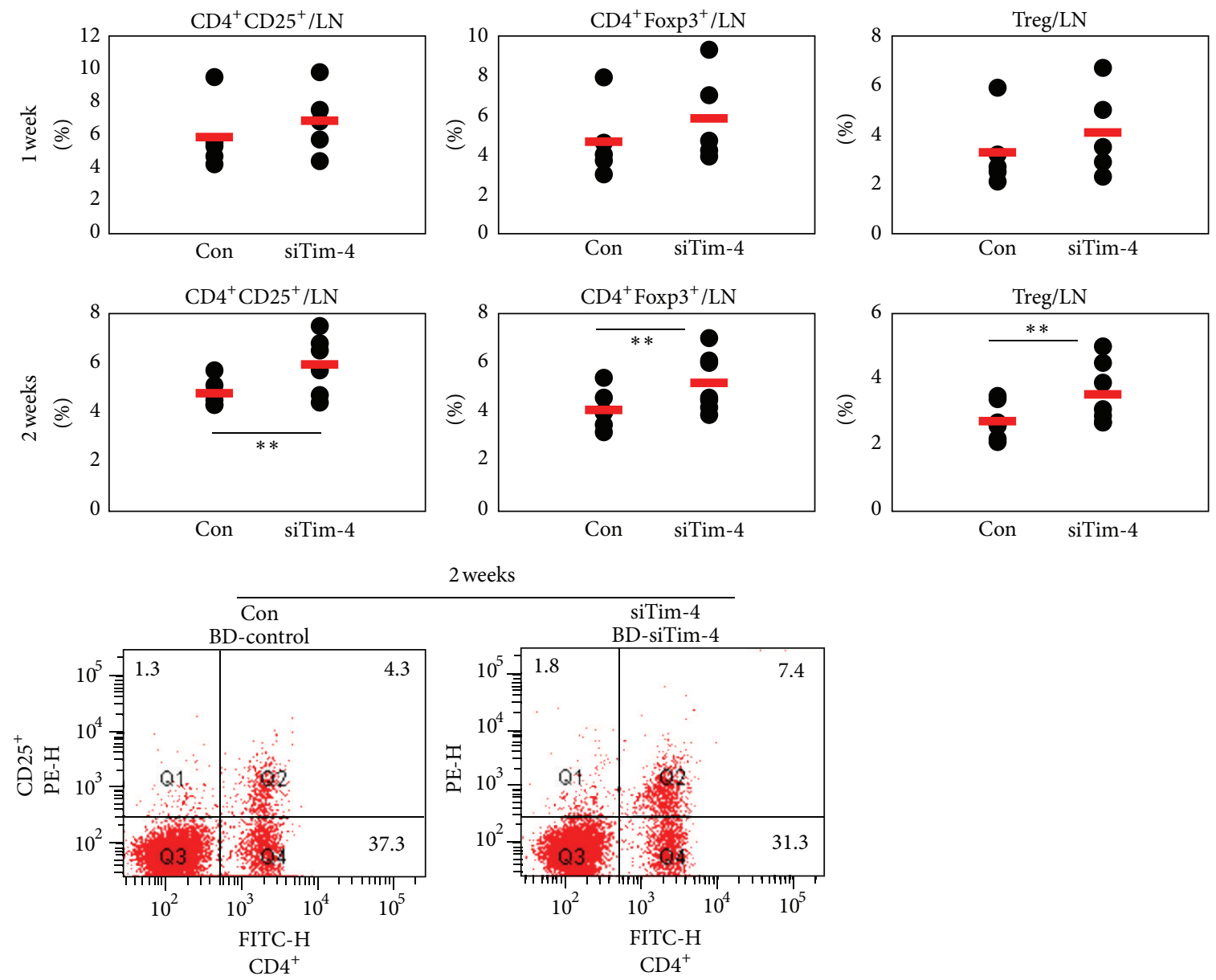

2 weeks

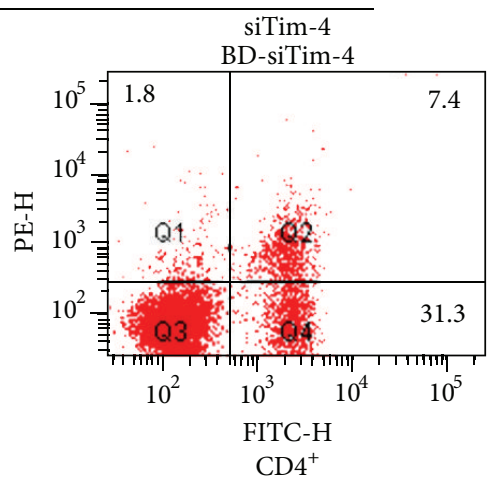

FIGURE 9: The frequencies of Treg cells were upregulated after treatment with siTim- 4 in Behçet's disease (BD) mice. Treg cells were confirmed by flow cytometry in lymph nodes of BD mice after treatment with siTim-4. At 1 and 2 weeks after the first treatment with siTim-4, the frequencies of $\mathrm{CD}^{+} \mathrm{CD} 25^{+}, \mathrm{CD} 4^{+} \mathrm{Foxp}^{+}$, and $\mathrm{CD} 4^{+} \mathrm{CD} 25^{+}$Foxp $3^{+}$Treg cells were compared between the siTim- 4 and control groups (negative control siRNA treated groups) $(n=5-7)\left({ }^{* *} P<0.05\right)$. The bottom panel shows $\mathrm{CD} 4^{+} \mathrm{CD} 25^{+}$in PBMCs at 2 weeks by FACS dot plot. Con: negative control siRNA injection to BD mice, siTim-4: Tim-4 siRNA injection to BD mice.

arthritis [40], inflammatory bowel disease [41], and SLE [42]. The anti-Tim-1 antibody (high avidity/agonistic) is a downregulator of pro-inflammatory Th-17 cells. TIM-1-TIM-4 interaction is involved in the regulation of Th cell responses and modulation of the Th1/Th2 cytokine balance [7]. Our data also indicate that administering the Tim- 1 vector decreased proinflammatory cytokines, such as IL-17, TNF- $\alpha$, and IL-6, but the Th2 type cytokine IL- 4 was upregulated in the Tim-1 vector injected group. Recently, upregulated cytokine IL-22 in ocular BD patients was also downregulated by anti-IL-6 and anti-TNF- $\alpha$ [37]. These results were similar to our results.

BD mice displayed markedly increased Tim-4 levels in LN and peritoneal macrophages compared to those in Nor and BDN mice. The frequencies of Tim $-4^{+}$cells were downregulated when Tim- 4 siRNA was administered to Nor mice compared to those in the NC group. siTim-4 administration to BD mice tended to decrease Tim $-4^{+}$cells in peritoneal macrophages. siTim- 4 administered BD mice displayed improved symptoms such as skin and genital ulcers and arthritis and showed a decreased severity score. But,
Tim $-4^{+}$cells related $\mathrm{T}$ cell phenotypes were not changed after siTim- 4 treatment. TIM- 4 is a ligand for TIM-1 [7] and is not expressed in T cells but is exclusively expressed in antigen-presenting cells, including DCs and macrophages $[9,10]$. Two groups have reported that Tim-4 deficient mice with a 129 or b6 background develop little or no autoimmunity $[9,43]$. In conjunction with improved symptoms, Treg cells in the siTim- 4 treated group were significantly upregulated compared to those in the control group, and IL17 level decreased. In our previous study, adoptive transfer of Treg cells to $\mathrm{BD}$ mice also improved BD-like symptoms [44]. In addition, the frequencies of Treg cells are lower in patients with autoimmune and inflammatory diseases, such as Crohn's disease [45], multiple sclerosis [46], and SLE [47], than those in healthy controls and inactive patients. The TIM-1-TIM-4 interaction is important for regulating $\mathrm{T}$ cell proliferation and modulating the Th1/Th2 cytokine balance [7]. Our data suggest that upregulated Treg cells induced by siTim- 4 might contribute to improve BD-like symptoms. 


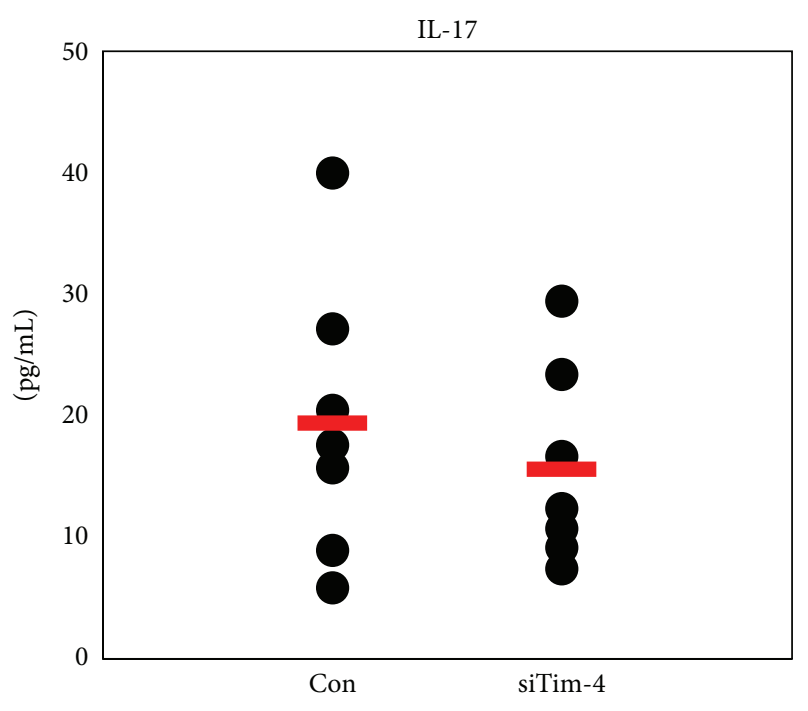

FIgURE 10: Administration of siTim-4 decreased serum level of IL17 in Behçet's disease (BD) mice. Serum obtained at 2 weeks after the first injection of siTim-4 and control (Con) in BD mice. The level of IL-17 was analyzed by ELISA $(n=8)$. Con: negative control siRNA injection to BD mice, siTim-4: Tim-4 siRNA injection to BD mice.

In conclusion, the frequencies of $\mathrm{Tim}-1^{+}$cells in $\mathrm{BD}$ mice were downregulated compared to those in BDN mice. Administering the Tim-1 vector to $\mathrm{BD}$ mice improved the BD-like symptoms and decreased the severity score by upregulating Treg cells and down-regulating pro-inflammatory cytokines. In addition, treatment with siTim- 4 upregulated Treg cells and improved BD-like symptoms, which were related to the Tim-1 and Tim-4 expression and the Tim-1Tim-4 interaction. Furthermore, Tim- 4 siRNA downregulated the level of IL-17, which may have been involved in improving the BD-like symptoms. Consequently, regulation of Tim-1 and Tim-4 was effective for improving BD-like symptoms in mice.

\section{Conflict of Interests}

There is no conflict of interest for this study.

\section{Authors' Contribution}

The Tim-1 vector was kindly provided by Professor Lawrence P. Kane from the University of Pittsburgh.

\section{Acknowledgment}

This study was supported by a Korea Science and Engineering Foundation (KOSEF) Grant R01-2008-000-20474-0, the Korean Health Technology R\&D Project, Ministry for Health, Welfare, and Family Affairs (A100535), and 2010-0011130 and 2013R1A1A3008248 from the National Research Foundation of Korea (NRF) by the Ministry of Education, Science, and Technology. Ju A. Shim performed the experiment, Eun-So
Lee discussed the results, Seonghyang Sohn designed the study, Ju A. Shim and Seonghyang Sohn wrote the paper.

\section{References}

[1] V. K. Kuchroo, D. T. Umetsu, R. H. DeKruyff, and G. J. Freeman, "The TIM gene family: emerging roles in immunity and disease," Nature Reviews Immunology, vol. 3, no. 6, pp. 454462, 2003.

[2] J. H. Meyers, C. A. Sabatos, S. Chakravarti, and V. K. Kuchroo, "The TIM gene family regulates autoimmune and allergic diseases," Trends in Molecular Medicine, vol. 11, no. 8, pp. 362369, 2005.

[3] G. Kaplan, A. Totsuka, P. Thompson, T. Akatsuka, Y. Moritsugu, and S. M. Feinstone, "Identification of a surface glycoprotein on African green monkey kidney cells as a receptor for hepatitis A virus," EMBO Journal, vol. 15, no. 16, pp. 4282-4296, 1996.

[4] D. Feigelstock, P. Thompson, P. Mattoo, Y. Zhang, and G. G. Kaplan, "The human homolog of HAVcr-1 codes for a hepatitis A virus cellular receptor," Journal of Virology, vol. 72, no. 8, pp. 6621-6628, 1998.

[5] W. K. Han, V. Bailly, R. Abichandani, R. Thadhani, and J. V. Bonventre, "Kidney Injury Molecule-1 (KIM-1): a novel biomarker for human renal proximal tubule injury," Kidney International, vol. 62, no. 1, pp. 237-244, 2002.

[6] T. Ichimura, J. V. Bonventre, V. Bailly et al., "Kidney injury molecule-1 (KIM-1), a putative epithelial cell adhesion molecule containing a novel immunoglobulin domain, is up-regulated in renal cells after injury," The Journal of Biological Chemistry, vol. 273, no. 7, pp. 4135-4142, 1998.

[7] J. H. Meyers, S. Chakravarti, D. Schlesinger et al., "TIM-4 is the ligand for TIM-1, and the TIM-1-TIM-4 interaction regulates T cell proliferation," Nature Immunology, vol. 6, no. 5, pp. 455464, 2005.

[8] S. E. Umetsu, W.-L. Lee, J. J. McIntire et al., "TIM-1 induces $\mathrm{T}$ cell activation and inhibits the development of peripheral tolerance," Nature Immunology, vol. 6, no. 5, pp. 447-454, 2005.

[9] R. Rodriguez-Manzanet, J. H. Meyers, S. Balasubramanian et al., "TIM-4 expressed on APCs induces T cell expansion and survival," Journal of Immunology, vol. 180, no. 7, pp. 4706-4713, 2008.

[10] M. Mizui, T. Shikina, H. Arase et al., "Bimodal regulation of $\mathrm{T}$ cell-mediated immune responses by TIM-4," International Immunology, vol. 20, no. 5, pp. 695-708, 2008.

[11] N. Kobayashi, P. Karisola, V. Peña-Cruz et al., "TIM-1 and TIM4 glycoproteins bind phosphatidylserine and mediate uptake of apoptotic cells," Immunity, vol. 27, no. 6, pp. 927-940, 2007.

[12] M. Miyanishi, K. Tada, M. Koike, Y. Uchiyama, T. Kitamura, and S. Nagata, "Identification of Tim4 as a phosphatidylserine receptor," Nature, vol. 450, no. 7168, pp. 435-439, 2007.

[13] C.-Q. Zhao, T.-L. Li, S.-H. He et al., "Specific immunotherapy suppresses Th2 responses via modulating TIM1/TIM4 interaction on dendritic cells," Allergy, vol. 65, no. 8, pp. 986-995, 2010.

[14] S.-C. Chae, J.-H. Song, J.-C. Heo, Y.-C. Lee, J.-W. Kim, and H.T. Chung, "Molecular variations in the promoter and coding regions of human Tim-1 gene and their association in Koreans with asthma," Human Immunology, vol. 64, no. 12, pp. 1177-1182, 2003.

[15] S.-C. Chae, J.-H. Song, Y.-C. Lee, J.-W. Kim, and H.-T. Chung, "The association of the exon 4 variations of Tim-1 gene with allergic diseases in a Korean population," Biochemical and 
Biophysical Research Communications, vol. 312, no. 2, pp. 346350, 2003.

[16] S.-C. Chae, Y.-R. Park, J.-H. Song, S.-C. Shim, K.-S. Yoon, and H.-T. Chung, "The polymorphisms of Tim-1 promoter region are associated with rheumatoid arthritis in a Korean population," Immunogenetics, vol. 56, no. 10, pp. 696-701, 2005.

[17] N. S. Page, G. Jones, and G. J. Stewart, "Genetic association studies between the $\mathrm{T}$ cell immunoglobulin mucin (TIM) gene locus and childhood atopic dermatitis," International Archives of Allergy and Immunology, vol. 141, no. 4, pp. 331-336, 2006.

[18] Y. Wang, J. Meng, X. Wang et al., "Expression of human TIM-1 and TIM-3 on lymphocytes from systemic lupus erythematosus patients," Scandinavian Journal of Immunology, vol. 67, no. 1, pp. 63-70, 2008.

[19] F. Ilhan, T. Demir, P. Türkçüoğlu, B. Turgut, N. Demir, and A. Gödekmerdan, "Th1 polarization of the immune response in uveitis in Behçet's disease," Canadian Journal of Ophthalmology, vol. 43, no. 1, pp. 105-108, 2008.

[20] T. Shimizu, G. E. Ehrlich, G. Inaba, and K. Hayashi, "Behcet disease (Behcet syndrome)," Seminars in Arthritis and Rheumatism, vol. 8, no. 4, pp. 223-260, 1979.

[21] H. Behçet, "Über rezidivierende, aphthöse, durch ein virus verursachte Geschwüre am Mund, am Auge und an den Genitalien," Dermatologische Wochenschrift, vol. 105, pp. 11521157, 1937.

[22] S. Lee, D. Bang, Y. H. Cho, E.-S. Lee, and S. Sohn, "Polymerase chain reaction reveals herpes simplex virus DNA in saliva of patients with Behçet's disease," Archives of Dermatological Research, vol. 288, no. 4, pp. 179-183, 1996.

[23] E. S. Lee, S. Lee, D. Bang, S. Sohn, C. Park, and K. Lee, "Herpes simplex virus detection by polymerase chain reaction in intestinal ulcer of patients with Behçet's disease," Journal of Investigative Dermatology, vol. 101, no. 3, p. 474, 1993.

[24] D. Bang, K. H. Yoon, H. G. Chung, E. H. Choi, E.-S. Lee, and S. Lee, "Epidemiological and clinical features of Behcet's disease in Korea," Yonsei Medical Journal, vol. 38, no. 6, pp. 428-436, 1997.

[25] E. Lee, S. Lee, D. Bang, and S. Sohn, "Detection of herpes simplex virus DNA by polymerase chain reaction in genital ulcer of patients with Behçet's disease," Revue du Rhumatisme, vol. 63, p. 532, 1996.

[26] S. Sohn, E.-S. Lee, D. Bang, and S. Lee, "Behcet's disease-like symptoms induced by the Herpes simplex virus in ICR mice," European Journal of Dermatology, vol. 8, no. 1, pp. 21-23, 1998.

[27] H. J. Kim, D. Bang, S. H. Lee et al., "Behcet's syndrome in Korea: a look at the clinical picture," Yonsei Medical Journal, vol. 29, no. 1, pp. 72-78, 1988.

[28] A. J. de Souza, T. B. Oriss, K. J. O’Malley, A. Ray, and L. P. Kane, "T cell Ig and mucin 1 (TIM-1) is expressed on in vivo-activated T cells and provides a costimulatory signal for T cell activation," Proceedings of the National Academy of Sciences of the United States of America, vol. 102, no. 47, pp. 17113-17118, 2005.

[29] J. Wu, Y. Song, A. B. H. Bakker et al., "An activating immunoreceptor complex formed by NKG2D and DAP10," Science, vol. 285, no. 5428, pp. 730-732, 1999.

[30] M. Ulker, K. D. Lewis, L. E. Hood, and I. Stroynowski, "Activated $\mathrm{T}$ cells transcribe an alternatively spliced mRNA encoding a soluble form of Qa-2 antigen," EMBO Journal, vol. 9, no. 12, pp. 3839-3847, 1990.

[31] O. Saitoh, N. Abiru, M. Nakahara, and Y. Nagayama, "CD8+CD122+ T cells, a newly identified regulatory $\mathrm{T}$ subset, negatively regulate graves' hyperthyroidism in a murine model," Endocrinology, vol. 148, no. 12, pp. 6040-6046, 2007.
[32] M. Rifa'i, Z. Shi, S.-Y. Zhang et al., "CD8+CD122+ regulatory $\mathrm{T}$ cells recognize activated $\mathrm{T}$ cells via conventional MHC class I $-\alpha \beta$ TCR interaction and become IL-10-producing active regulatory cells," International Immunology, vol. 20, no. 7, pp. 937-947, 2008.

[33] L. Xiao, Z.-R. Fu, F. Liu et al., "Suppression of allograft rejection by Tim-1-Fc through cross-linking with a novel Tim-1 binding partner on T cells," PLoS ONE, vol. 6, no. 7, Article ID e21697, 2011.

[34] D. J. Cua, J. Sherlock, Y. Chen et al., "Interleukin-23 rather than interleukin-12 is the critical cytokine for autoimmune inflammation of the brain," Nature, vol. 421, no. 6924, pp. 744748, 2003.

[35] C. L. Langrish, Y. Chen, W. M. Blumenschein et al., "IL-23 drives a pathogenic $T$ cell population that induces autoimmune inflammation," The Journal of Experimental Medicine, vol. 201, no. 2, pp. 233-240, 2005.

[36] D. Yen, J. Cheung, H. Scheerens et al., "IL-23 is essential for T cell-mediated colitis and promotes inflammation via IL-17 and IL-6," The Journal of Clinical Investigation, vol. 116, no. 5, pp. 1310-1316, 2006.

[37] S. Sugita, Y. Kawazoe, A. Imai et al., "Role of IL-22- and TNF- $\alpha$ producing Th22 cells in uveitis patients with Behcet's disease," Journal of Immunology, vol. 190, no. 11, pp. 5799-5808, 2013.

[38] T. Cai, Q. Wang, Q. Zhou et al., "Increased expression of IL-22 is associated with disease activity in Behcet's disease," PlosOne, vol. 8, no. 3, Article ID e59009, 2013.

[39] C. K. Edwards III, "Drug discovery and development for inflammatory diseases," Expert Opinion on Therapeutic Targets, vol. 8, no. 2, pp. 151-163, 2004.

[40] N. Nishimoto and T. Kishimoto, "Humanized antihuman IL6 receptor antibody, tocilizumab," Handbook of Experimental Pharmacology, no. 181, pp. 151-160, 2008.

[41] J. Mudter and M. F. Neurath, "IL-6 signaling in inflammatory bowel disease: pathophysiological role and clinical relevance," Inflammatory Bowel Diseases, vol. 13, no. 8, pp. 1016-1023, 2007.

[42] H.-Y. Chun, J.-W. Chung, H.-A. Kim et al., "Cytokine IL-6 and IL-10 as biomarkers in systemic lupus erythematosus," Journal of Clinical Immunology, vol. 27, no. 5, pp. 461-466, 2007.

[43] K. Wong, P. A. Valdez, C. Tan, S. Yeh, J.-A. Hongo, and W. Ouyang, "Phosphatidylserine receptor Tim-4 is essential for the maintenance of the homeostatic state of resident peritoneal macrophages," Proceedings of the National Academy of Sciences of the United States of America, vol. 107, no. 19, pp. 8712-8717, 2010.

[44] J. Shim, E.-S. Lee, S. Park, D. Bang, and S. Sohn, "CD4+ CD25+ regulatory T cells ameliorate Behcet's disease-like symptoms in a mouse model," Cytotherapy, vol. 13, no. 7, pp. 835-847, 2011.

[45] I. Ricciardelli, K. J. Lindley, M. Londei, and S. Quaratino, "Anti tumour necrosis- $\alpha$ therapy increases the number of FOXP3 + regulatory T cells in children affected by Crohn's disease," Immunology, vol. 125, no. 2, pp. 178-183, 2008.

[46] J. Huan, N. Culbertson, L. Spencer et al., "Decreased FOXP3 levels in multiple sclerosis patients," Journal of Neuroscience Research, vol. 81, no. 1, pp. 45-52, 2005.

[47] H.-Y. Lee, Y.-K. Hong, H.-J. Yun, Y.-M. Kim, J.-R. Kim, and W.-H. Yoo, "Altered frequency and migration capacity of CD4+ CD25+ regulatory T cells in systemic lupus erythematosus," Rheumatology, vol. 47, no. 6, pp. 789-794, 2008. 


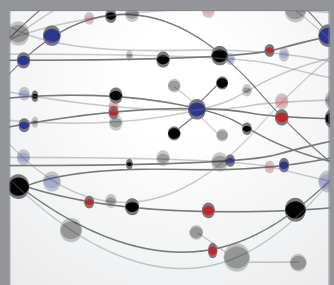

The Scientific World Journal
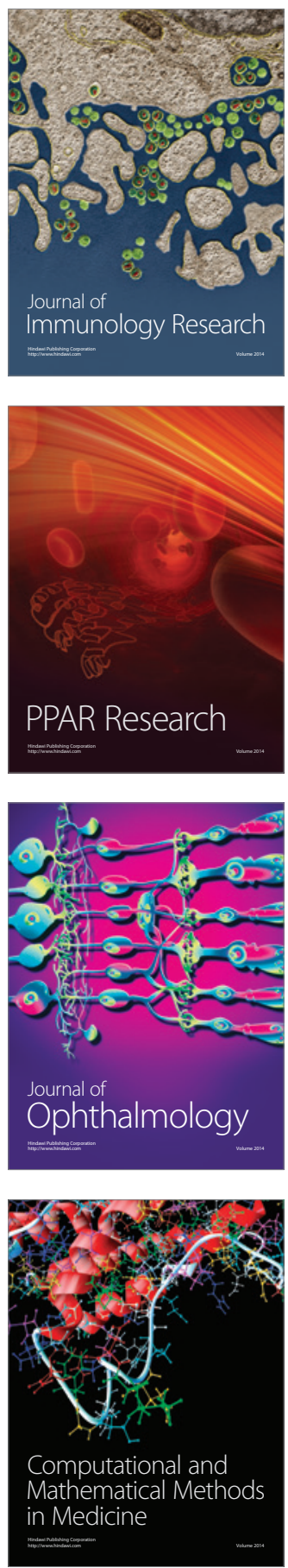

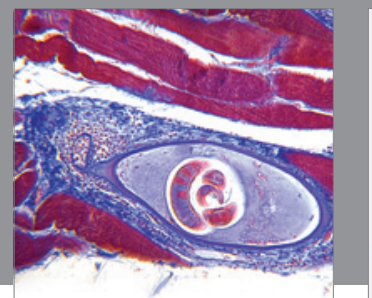

Gastroenterology

Research and Practice
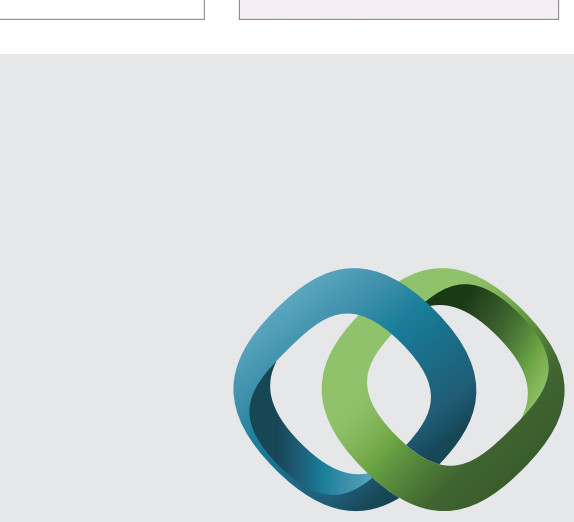

\section{Hindawi}

Submit your manuscripts at

http://www.hindawi.com
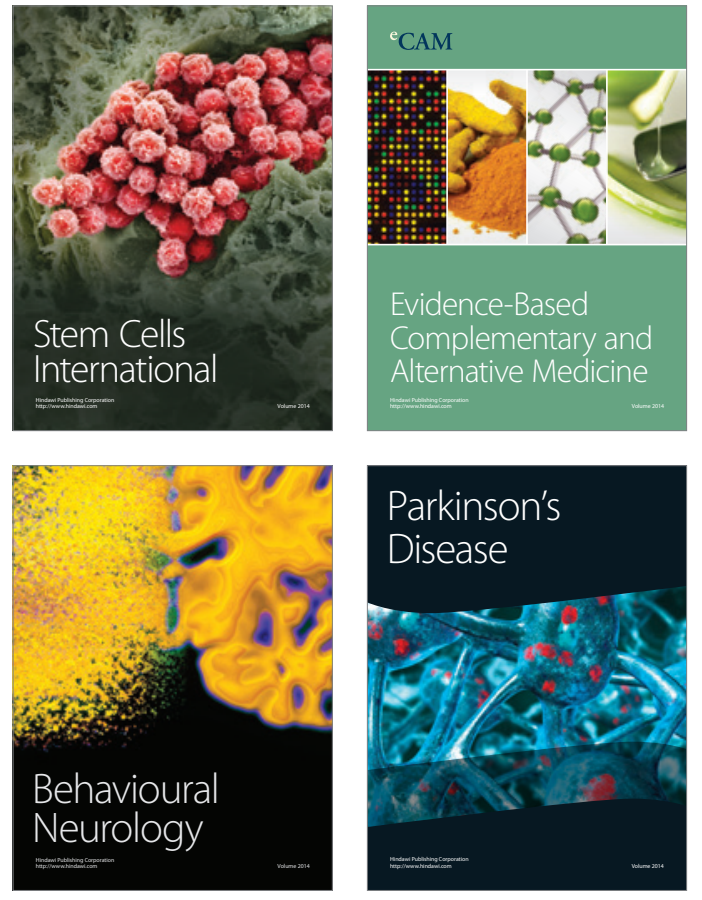
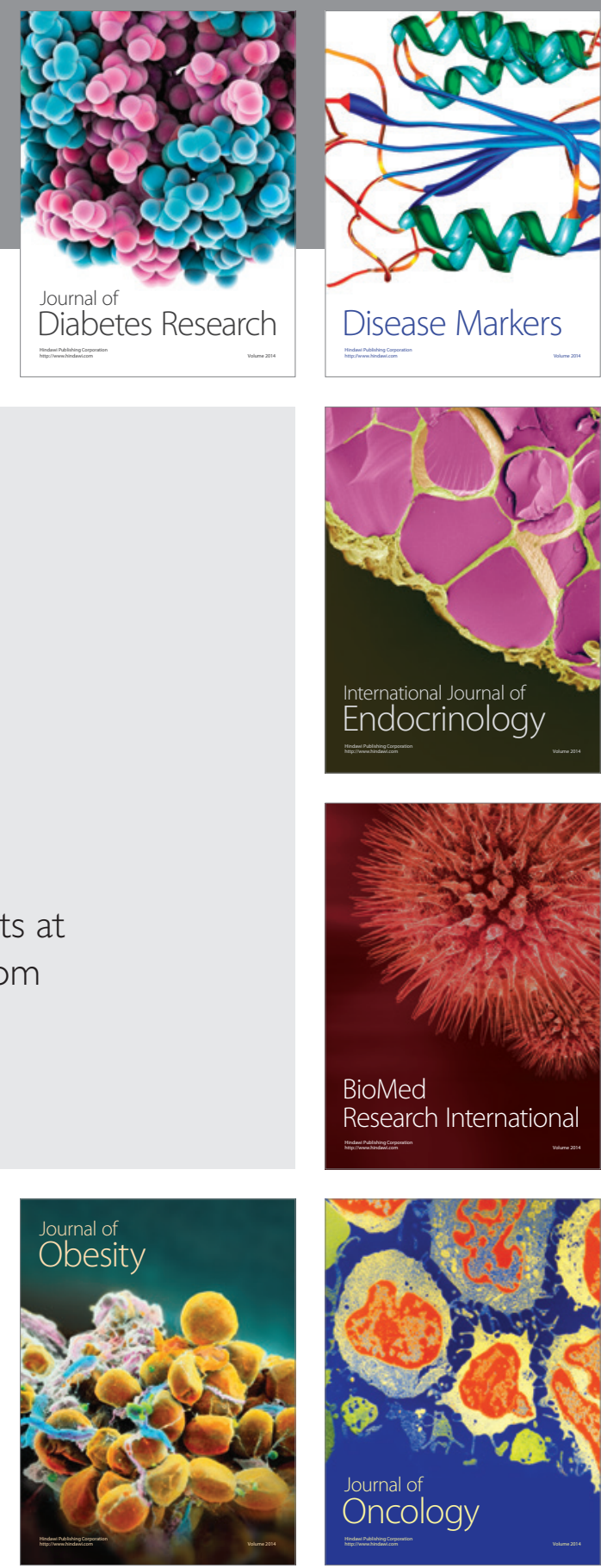

Disease Markers
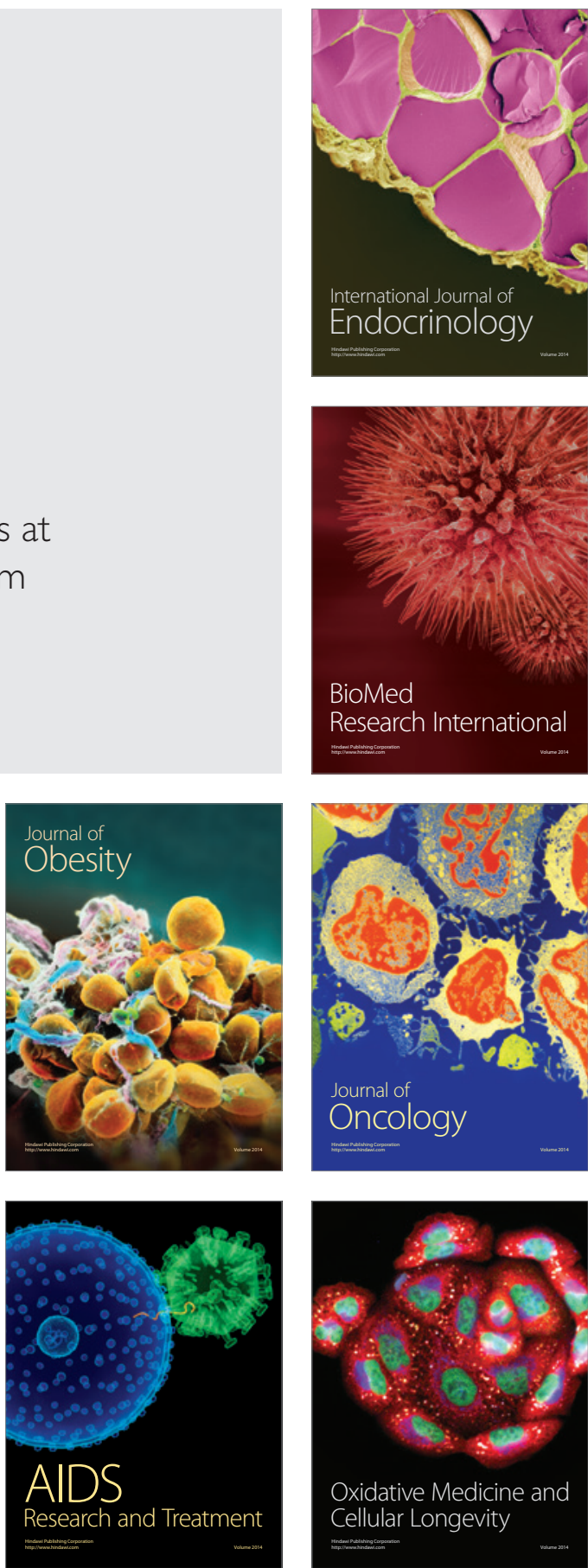